\title{
Interaction of Deuterium Plasma with Sputter-deposited Tungsten Nitride Films
}

\author{
L. Gao ${ }^{1,2}$, W. Jacob ${ }^{* 1}$, G. Meisl ${ }^{1}$, T. Schwarz-Selinger ${ }^{1}$, T. Höschen ${ }^{1}$, U. von Toussaint ${ }^{1}$ and T. Dürbeck ${ }^{1}$ \\ 1. Max-Planck-Institut für Plasmaphysik, Boltzmannstr. 2, 85748 Garching, Germany \\ 2. Institute of Plasma Physics, Chinese Academy of Sciences, Shushanhu Rd. 350, 230031 Hefei, China
}

\begin{abstract}
Magnetron-sputtered tungsten nitride $\left(\mathrm{WN}_{\mathrm{x}}\right)$ films were used as a model system to study the behavior of re-deposited $\mathrm{WN}_{\mathrm{x}}$ layers which could form in fusion devices with tungsten (W) wall during nitrogen seeding. The interaction of such $\mathrm{WN}_{\mathrm{x}}$ layers with deuterium (D) plasmas was investigated in dedicated laboratory experiments. D retention and $\mathrm{N}$ removal due to $\mathrm{D}$ plasma exposure (D flux: $9.9 \times 10^{19} \mathrm{D} \cdot \mathrm{m}^{-2} \mathrm{~s}^{-1}$, ion energy $215 \mathrm{eV}$ ) at different temperatures were measured with ion beam analysis (IBA). Low-energy argon sputtering followed by IBA was applied to resolve the $\mathrm{D}$ distribution in the top-most surface of $\mathrm{WN}_{\mathrm{x}}$ with significantly improved depth resolution compared with the standard D depth profiling method by nuclear reaction analysis. Experimentally determined thicknesses for the penetration of $\mathrm{D}$ in $\mathrm{WN}_{\mathrm{x}}$ were compared with the penetration depth for D calculated in SDTrimSP simulations. Results show that D is only retained within the ion penetration range for samples exposed at $300 \mathrm{~K}$. In contrast to the $300 \mathrm{~K}$ case, D diffuses beyond the implantation depth in a sample exposed at $600 \mathrm{~K}$. However, the D penetration depth is much lower than in pure $\mathrm{W}$ at comparable conditions. The total amount of retained $\mathrm{D}$ in $\mathrm{WN}_{\mathrm{x}}$ at $600 \mathrm{~K}$ is by $50 \%$ lower than for implantation at $300 \mathrm{~K}$ with the same D fluence. Nitrogen is removed only within the D ion range.
\end{abstract}

Key words: Plasma wall interaction; Tungsten; Nitrogen seeding; Tungsten nitride; Deuterium retention; Deuterium-rich surface layer.

PACS: 28.52.Fa, 52.40.Hf, 79.20.Rf, 52.77.Bn

$\begin{array}{ll}\text { Published in: } & \text { Nuclear Fusion } 56 \text { (2016) } 016004 . \\ \text { doi: } & 10.1088 / 0029-5515 / 56 / 1 / 016004 \\ \text { Submitted: } & 27.07 .2015 \\ \text { Accepted: } & 29.10 .2015 \\ \text { Available online: } & 25.11 .2015\end{array}$

${ }^{*}$ Corresponding author. Fax: +49-3299-1504, Tel: +49-3299-2618.

E-mail address: wolfgang.jacob@ipp.mpg.de 


\section{Introduction}

Interaction of the boundary plasma with the plasma-facing surfaces will lead to erosion and deposition of wall materials and fuel retention in the plasma-facing components. Retention of hydrogen isotopes, especially in next generation fusion devices where a mixture of deuterium (D) and tritium (T) will be used as fuel, is of great importance due to safety and cost concerns [1]. For fusion devices with all-metal walls, such as ASDEX Upgrade and JET, impurity seeding is necessary for radiative power dissipation to reduce the peak power load onto the divertor [2,3]. Recent experiments in ASDEX Upgrade using a full-W first wall [4-6] and JET with the ITER-like Wall [7, 8 and references therein] had shown that nitrogen has favorable properties in cooling the edge plasma and enhancing plasma performance. The presence of $\mathrm{N}_{2}$ as a new plasma species will lead to additional plasma-surface interactions such as implantation, retention, sputtering and possibly co-deposition together with sputtered W. Co-deposited $\mathrm{WN}_{\mathrm{x}}$ layers were already observed in TEXTOR after $\mathrm{N}_{2}$-seeded discharges [9] and the sputtering of $\mathrm{WN}_{\mathrm{x}}$ layers by seed impurities (Ar and $\mathrm{Ne}$ ) was investigated by Dobes et al. [10]. So far there are no publications on the interaction of D plasma with co-deposited $\mathrm{WN}_{\mathrm{x}}$ layers in fusion devices during or after nitrogen seeding. For a reliable assessment of the plasma-surface-interaction behavior and the hydrogen-isotope inventory in nitrogen containing $\mathrm{W}$, it is mandatory to investigate the retention and diffusion of $\mathrm{D}$ in such $\mathrm{WN}_{\mathrm{x}}$ layers.

Recent experiments $[11,12]$ have indicated that the formation of $\mathrm{WN}_{\mathrm{x}}$ or the presence of a $\mathrm{N}$-containing layer formed by $\mathrm{N}$ implantation reduces reemission of $\mathrm{D}$ through the surface compared with pure $\mathrm{W}$ thus leading to increased D retention at elevated temperature. In our preceding study [13], sputter-deposited $\mathrm{WN}_{\mathrm{x}}$ films deposited on bulk $\mathrm{W}$ substrates were exposed to D plasma at $300 \mathrm{~K}$ for studying the behavior of co-deposited $\mathrm{WN}_{\mathrm{x}}$ layers in fusion devices during or after discharges with $\mathrm{N}_{2}$ seeding. Results showed that $\mathrm{D}$ implanted at $300 \mathrm{~K}$ into $\mathrm{WN}_{\mathrm{x}}$ films is retained only in a very thin layer with a thickness comparable to the ion penetration range of the impinging $\mathrm{D}$ ions and does not, as in bulk $\mathrm{W}$, diffuse to larger depth. In the present work, we extend this study to higher temperature $(600 \mathrm{~K})$ and make comparison with $300-\mathrm{K}$ exposures. Low-energy argon sputtering combined with ex-situ ion beam analysis (IBA) [13] after D exposure was applied to determine the $\mathrm{D}$ depth profiles in the top-most surface. Additional attention was paid on the erosion of the $\mathrm{WN}_{\mathrm{x}}$ films by D plasma using both IBA and XPS measurements. Furthermore, the thermal release behavior of $\mathrm{N}$ and $\mathrm{D}$ from $\mathrm{WN}_{\mathrm{x}}$ films was investigated by temperature programmed desorption (TPD). Based on this, the $\mathrm{D}$ retention and its diffusion behavior in sputter-deposited $\mathrm{WN}_{\mathrm{x}}$ layers exposed to low-flux D plasma will be discussed. Finally, the N removal was measured as a function of D fluence which is expected to be helpful for understanding $\mathrm{N}$ migration in edge plasmas.

\section{Experimental details}

\subsection{Sample preparation}

Single crystal (100) silicon wafers were cut into pieces with area of $10 \times 10 \mathrm{~mm}^{2}$ as substrates for film deposition. All the Si pieces were then ultrasonically cleaned in propanol and acetone. A W film was deposited as an interlayer before and $\mathrm{WN}_{\mathrm{x}}$ films were grown onto these $\mathrm{Si}$ substrates. There are two reasons why $\mathrm{WN}_{\mathrm{x}}$ films were not directly deposited onto Si substrates. First, since samples shall later be exposed at elevated temperature, a W film as interlayer will avoid the possible interaction of $\mathrm{N}$ with $\mathrm{Si}$ during heat treatment. Second, Si shows similar to $\mathrm{N}$ also a nuclear reaction with ${ }^{4} \mathrm{He}$ and the proton spectra from $\mathrm{N}$ and Si overlap. The silicon signal can be suppressed when the $\mathrm{W}$ interlayer is thicker than $\sim 2 \mu \mathrm{m}$.

The depositions were performed using a commercial sputtering device (Discovery ${ }^{\circledR} 18$, Denton). The system was pumped down to a base pressure of less than $5 \times 10^{-5} \mathrm{~Pa}$. A liquid $\mathrm{N}_{2}$ cold trap was used to reduce the water partial pressure. Prior to deposition the Si substrates were etched with argon for 2 min (0.5 Pa 
Ar). The applied RF power of $100 \mathrm{~W}$ resulted in a substrate bias voltage of $-580 \mathrm{~V}$ for surface etching. W film deposition was performed in an atmosphere of $0.7 \mathrm{~Pa}$ Ar for $120 \mathrm{~min}$. With an applied DC power of $300 \mathrm{~W}$ a cathode bias of $-380 \mathrm{~V}$ was generated. According to our previous results $[14,15]$, the deposition rate of $\mathrm{W}$ film under these conditions is about $18.5 \mathrm{~nm} / \mathrm{min}$. Therefore, $120 \mathrm{~min}$ deposition will give rise to a $2.2 \mu \mathrm{m}$ thick $\mathrm{W}$ film. $\mathrm{WN}_{\mathrm{x}}$ layers $\left(0.6 \mathrm{~Pa}, 50 \% \mathrm{Ar}, 50 \% \mathrm{~N}_{2}, 300 \mathrm{~W} \mathrm{RF}\right.$ power resulting in $-370 \mathrm{~V}$ cathode bias) were in the following deposited on top of the $\mathrm{W}$ films for 5 and $15 \mathrm{~min}$, respectively. No additional substrate bias was applied for the deposition of the $\mathrm{W}$ and $\mathrm{WN}_{\mathrm{x}}$ layers. To ensure a homogeneous thickness for all the samples, the substrate holder was rotating through the whole deposition process. In order to avoid a possible contamination of the $\mathrm{W}$ surface, the $\mathrm{WN}_{\mathrm{x}}$ layers were deposited immediately after $\mathrm{W}$ film deposition without breaking the vacuum. One of the Si substrates was partially covered by adhesive Kapton tape. Removing the tape after deposition produced a step which allowed measuring the thickness of the complete deposited layer system by tactile profilometry. The full layer system with 15 min $\mathrm{WN}_{\mathrm{x}}$ deposition was about $2.35 \mu \mathrm{m}$ thick which indicated that the thicker $\mathrm{WN}_{\mathrm{x}}$ layers were about $150 \mathrm{~nm}$ thick. The precise thickness of the $\mathrm{WN}_{\mathrm{x}}$ layer was determined from a cross-section image. From the cross section produced in a scanning electron microscope equipped with a focused-ion-beam the layer thicknesses were measured to be $135 \pm 5 \mathrm{~nm}$ for the thicker samples and $45 \pm 5 \mathrm{~nm}$ for 5 -min-deposited samples. One set of thicker samples and one thinner sample were annealed in vacuum at a temperature of $600 \mathrm{~K}$ for 2 hours. The annealed thicker samples were later exposed to D plasma at $300 \mathrm{~K}$ together with the as-deposited layers. This was done to allow distinguishing the effect of exposure temperature on $\mathrm{D}$ retention from possible annealinginduced structural changes within the sputter-deposited $\mathrm{WN}_{\mathrm{x}}$ films at $600 \mathrm{~K}$. The annealed thinner sample was used for thermal decomposition measurements (see next section). This thin film is assumed to show the same thermal behavior as the $135 \mathrm{~nm}$ thick films.

\subsection{Thermal stability of WNx layer}

Since some of the deposited $\mathrm{WN}_{\mathrm{x}}$ layers were exposed to D plasma at $600 \mathrm{~K}$, it was necessary to study the thermal stability of the present $\mathrm{WN}_{\mathrm{x}}$ films, i.e., to determine at which temperature the used $\mathrm{WN}_{\mathrm{x}}$ layers start to decompose. For this, temperature programmed desorption (TPD) was used. TPD measurements were performed in the quartz tube of the TESS device [16]. The temperature response of the samples to the linear oven temperature ramp was calibrated in independent experiments by a thermocouple connected to a Si wafer of identical size. The samples were heated with an oven heating rate of $15 \mathrm{~K} / \mathrm{min}$ up to a sample temperature of $1273 \mathrm{~K}$, which is expected to be high enough to ensure desorption of all $\mathrm{N}$ from the layers.

The desorbed gases were measured with a quadrupole mass spectrometer (QMS). The secondary electron multiplier of the QMS was operated in single ion counting mode to minimize the background noise and to be able to apply Poisson statistics for determining the accuracy. The following 8 masses were recorded as a function of time: 12,14, 16, 20, 28, 32, 40, and $44 \mathrm{amu}$ /q. For the quantitative analysis the QMS signals for $\mathrm{N}_{2}$ was calibrated with pure $\mathrm{N}_{2}$ gas. For this purpose a constant gas flow was introduced into the UHV chamber through a calibrated orifice and the QMS signal was measured. With the orifice size and the upstream pressure measured with a spinning rotor gauge a calibration factor for $\mathrm{N}_{2}$ of $3.8 \times 10^{9} \mathrm{~N}_{2}$ molecules per count was deduced. The experimental uncertainty was determined by consecutive calibration measurements and was governed by the stability of the detector rather than by determination of the flow. As a result, the inaccuracy of the present TPD measurement for quantification of $\mathrm{N}$ is better than $10 \%$. 


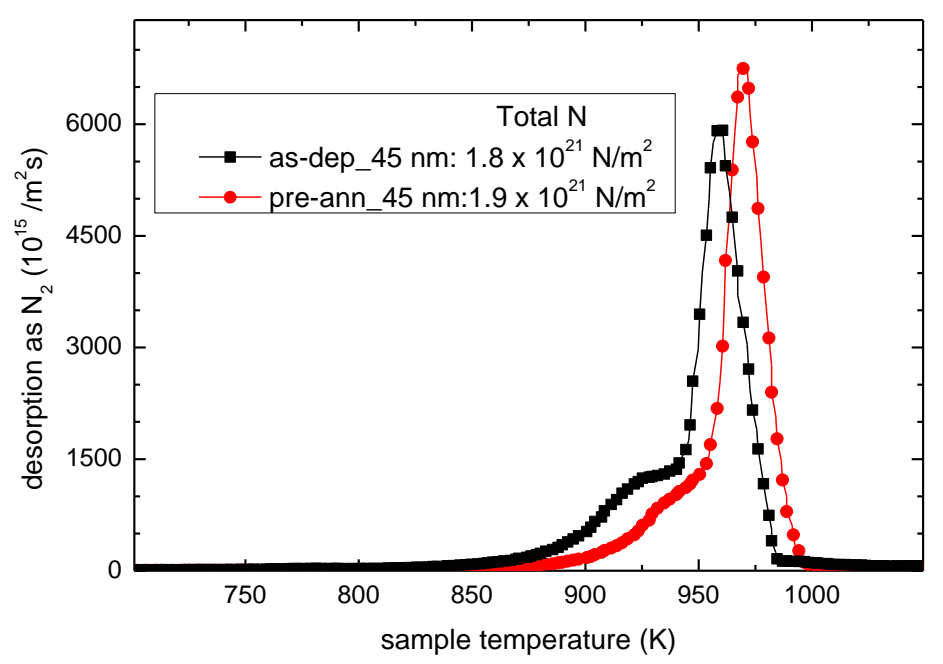

Fig. 1: TPD spectra on $N_{2}$ release from a $45 \mathrm{~nm}$ thick magnetron-sputtered $W N_{x}$ films deposited on 2- $\mu m$ W-coated-Si substrates.

Thinner $\mathrm{WN}_{\mathrm{x}}$ layers (about $45 \mathrm{~nm}$ ) on top of $\mathrm{W}$-coated Si substrates were used for TPD measurements. The TPD spectra of the as-deposited and the $\mathrm{WN}_{\mathrm{x}}$ layer annealed for $2 \mathrm{~h}$ at $600 \mathrm{~K}$ are shown in Fig. 1 . Decomposition of both as-deposited and annealed $\mathrm{WN}_{\mathrm{x}}$ layers starts at around $830 \mathrm{~K}$. The release spectra are composed of two release peaks. The first one is a shoulder at lower temperature followed by the main peak. The height of the shoulder is about $20 \%$ of the main peak. The peak positions for the as-deposited $\mathrm{WN}_{\mathrm{x}}$ layer are 925 and $960 \mathrm{~K}$ and for the $\mathrm{WN}_{\mathrm{x}}$ layer previously 940 and $970 \mathrm{~K}$. The integral of the release peaks over time, which is directly proportional to the total released $\mathrm{N}_{2}$ amount (as stated in the figure), is identical within the experimental uncertainty for both layers. The shift of the release spectrum of the preannealed layer to higher temperatures is presently unexplained. It might be explained by a transformation to a slightly more stable phase during annealing. Actually, X-ray diffraction measurements on thick WNx layers $(2 \mu \mathrm{m})$ grown in the same way before and after annealing at $600 \mathrm{~K}$ for 2 hours showed no measurable difference on the acquired diffraction pattern. But, of relevance for the present investigation is the fact that $\mathrm{N}_{2}$ release starts only at temperatures of about $830 \mathrm{~K}$ which is much higher than the annealing and the selected D implantation temperatures of $600 \mathrm{~K}$. In addition, the fact that the peak integrals of the asdeposited and of the annealed layers are identical clearly shows that during the $2 \mathrm{~h}$ annealing at $600 \mathrm{~K}$ no measurable loss of nitrogen from the layer occurs. Therefore this shift is of no relevance for the present investigation. Assuming that the $\mathrm{WN}_{\mathrm{x}}$ films deposited onto the side faces of the Si substrate increase the total $\mathrm{WN}_{\mathrm{x}}$-covered area by about $15 \%$ compared with the top surface area only, the $\mathrm{N}$ amount measured by TPD is in good agreement with the nitrogen amount determined by ion beam analysis presented further below. Unfortunately it was not possible to check if there was still $\mathrm{N}$ remaining in the layer after TPD measurements, because all the deposited layers delaminated from the substrate due to the largely different thermal expansion compared to the Si substrates.

Schmid et al. [17] investigated the interaction of nitrogen plasmas with W surfaces. In their article they also calculated the phase diagram for $\mathrm{W}: \mathrm{N}$ based on available thermodynamic data. According to these theoretical results W:N should be thermodynamically stable up to $600 \mathrm{~K}$ and start to decompose at higher temperatures. But they have also shown that although the $\mathrm{N}$ content in $\mathrm{N}$-implanted $\mathrm{W}$ surfaces starts to decrease for temperatures higher than $600 \mathrm{~K}, \mathrm{~N}$ was still retained in $\mathrm{W}$ for temperatures up to $800 \mathrm{~K}$. These 
experimental findings are in reasonable agreement with our result on the thermal stability of sputterdeposited $\mathrm{WN}_{\mathrm{x}}$ films.

\subsection{D implantation}

D implantation was performed in the low-pressure electron cyclotron resonance (ECR) plasma chamber 'PlaQ'. PlaQ was described before and the details can be found in Ref. [18]. At the used pressure of 1.0 Pa the $\mathrm{D}$ plasma delivers predominantly $\mathrm{D}_{3}{ }^{+}$ions $(94 \%)$ with minor contributions of $\mathrm{D}_{2}{ }^{+}(3 \%)$ and $\mathrm{D}^{+}(3 \%)$ [18]. D plasma was burned-in for 15 min without exposing the sample to the plasma beam by closing the shutter between the aperture and the sample holder. A DC bias voltage was applied to the substrate holder once the shutter was opened. The $-200 \mathrm{~V}$ DC bias voltage together with the plasma potential of about $15 \mathrm{eV}$ [18] resulted in an ion energy of $215 \mathrm{eV}$. For the dominant ion species $\mathrm{D}_{3}{ }^{+}$this corresponds to an energy of $72 \mathrm{eV}$ per deuteron and correspondingly to $108 \mathrm{eV}$ per $\mathrm{D}$ for the $\mathrm{D}_{2}{ }^{+}$ions and $215 \mathrm{eV}$ per $\mathrm{D}$ for the $\mathrm{D}^{+}$ions. The total $\mathrm{D}$ flux was $9.9 \times 10^{19} \mathrm{D} \cdot \mathrm{m}^{-2} \mathrm{~s}^{-1}$. D plasma exposures with fluences ranging from $1.0 \times 10^{23} \mathrm{D} / \mathrm{m}^{2}$ to $6.0 \times 10^{24} \mathrm{D} / \mathrm{m}^{2}$ were performed for the three different sets of samples at two different sample temperatures. Namely as-deposited samples were exposed at $300 \mathrm{~K}$ and $600 \mathrm{~K}$, and $600 \mathrm{~K}$ preannealed samples at $300 \mathrm{~K}$. The samples were mounted with screws at tungsten coated copper (temperature range: $230-450 \mathrm{~K})$ or stainless steel $(450-800 \mathrm{~K})$ holder. The rise of the temperature at the sample surfaces due to the ion bombardment was monitored by an infrared camera. The sample temperature was controlled by keeping the cooled holder at $\sim 295 \mathrm{~K}$ with a thermostat circuit of ethanol cooling and with radiative heating at $\sim 575 \mathrm{~K}$ for the heated holder, respectively. By this, the temperature at the sample surface was stabilized at 300 respectively $600 \mathrm{~K}$. Note that the D implantations at $600 \mathrm{~K}$ were not performed for preannealed samples, since a comparable annealing effect will occur during heating of the samples to steady state temperature prior to starting the D plasma exposure anyway. Also, the radiative heating was switched off 2 min before ending the implantation with the set $\mathrm{D}$ fluence. After switching off the plasma the cooling of the heated holder was assisted by increasing the $\mathrm{D}_{2}$ pressure in the main chamber to $500 \mathrm{~Pa}$. This increases the cooling rate by convection and heat conduction compared to cooling in vacuum.

\section{$2.4 X$-ray photoelectron Spectroscopy (XPS)}

X-ray photoelectron spectroscopy (XPS) measurements were performed using a Perkin Elmer PHI 5600 ESCA system with a hemispherical analyzer. The standard X-ray source was used to record spectra with $\mathrm{Mg}-\mathrm{K} \alpha$ radiation $(1253.6 \mathrm{eV})$. The Omni focus lens restricted the analyzed area to a spot with a diameter of $400 \mu \mathrm{m}$. The analyzer was operated at constant pass energy of $5.85 \mathrm{eV}$. Energy calibration for all the measurements were performed using pure $\mathrm{Au}, \mathrm{Ag}$ and $\mathrm{Cu}$ samples and a precision of $0.1 \mathrm{eV}$ was confirmed. For depth profiling an $10 \mathrm{kV} \mathrm{Ar}{ }^{+}$ion beam was scanned over an area of $1500 \times 1200 \mu \mathrm{m}^{2}$. The angle of incidence for the $\mathrm{Ar}^{+}$ion beam was $20^{\circ}$ to the surface normal. For evaluation of the measured XPS spectra a Shirley background function was applied for background subtraction. Standard relative sensitivity factors supplied by the manufacturer were used to estimate atomic concentrations.

\subsection{Ion Beam Analysis}

To investigate the D retention in the sample and the erosion of $\mathrm{WN}_{\mathrm{x}}$, the samples before and after plasma exposure were characterized by ion beam analysis. Nuclear reaction analysis (NRA) was applied for measuring the retained $\mathrm{D}$ amount with $\mathrm{D}\left({ }^{3} \mathrm{He}, \mathrm{p}\right){ }^{4} \mathrm{He}$ nuclear reaction and ${ }^{4} \mathrm{He}$ Rutherford backscattering spectroscopy (RBS) was used for determining the erosion of $\mathrm{WN}_{\mathrm{x}}$ films. The produced high energy protons from NRA were counted using a thick, large angle solid state detector at a scattering angle of $135^{\circ}$ equipped with a curved slit reducing the solid angle to $29.9 \mathrm{msr}$. In the experiments presented here 
a ${ }^{3} \mathrm{He}^{+}$ion beam with an energy of $500 \mathrm{keV}$ was used to determine the near surface $\mathrm{D}$ distribution by NRA. We define the information depth for the NRA analysis as the depth where the kinetic energy of the projectiles decreased to about $420 \mathrm{keV}$ (the energy where the cross-section is $10 \%$ as the maximum value at $620 \mathrm{keV}$ [19]) for the present nuclear reaction. This information depth was calculated applying SIMNRA [20] with Ziegler/Biersack stopping power data. The generated protons have a very high energy of about 13.5 MeV. The mean free path of these high energy protons is much larger than this information depth, such that the generated protons can easily reach the detector. At $500 \mathrm{keV}$, the NRA information depth in $\mathrm{WN}_{\mathrm{x}}$ is $680 \mathrm{~nm}$ for the high energy protons. For the given experimental geometry, the corresponding depth resolution from protons at the surface is $110 \mathrm{~nm}$ according to RESOLNRA [20]. For the produced $\alpha$ particles, the depth resolution is better due to the much stronger stopping by the material than for the highenergy protons. For our experimental setup the best achievable resolution for $\alpha$ particles at $500 \mathrm{keV}$ projectile energy is roughly $16 \mathrm{~nm}$. For the method presented here only the proton signal was evaluated because it provides a four times higher count rate for our experimental setup. The D amount in the sample was quantified using the cross section published by Alimov et al. [19]. For comparison and reference an about $10 \mathrm{~nm}$ thick plasma-deposited amorphous deuterated carbon film (a-C:D) on a Si wafer with a D amount of $6.7 \times 10^{20} \mathrm{D}$ atoms $/ \mathrm{m}^{2}$ was also measured by the same ${ }^{3} \mathrm{He}$ ion beam. The NRA information depth in a-C:D is larger than the above stated values for $\mathrm{WN}_{\mathrm{x}}$ so that the full a-C:D layer contributes to the NRA proton signal.

The erosion of the $\mathrm{WN}_{\mathrm{x}}$ layers was measured by RBS using $1.5 \mathrm{MeV}^{4} \mathrm{He}^{+}$projectiles. The backscattered ${ }^{4} \mathrm{He}$ particles were counted with a detector at a scattering angle of $165^{\circ}$ with a solid angle of $1.10 \mathrm{msr}$. The measured RBS spectra were simulated with SIMNRA [20] using Ziegler/Biersack stopping power data and taking dual scattering into account. Based on this simulation the $\mathrm{N}$ amount before and after $\mathrm{D}$ implantation and the removed layer thickness due to D plasma exposure were determined.

\subsection{Low-energy Ar sputtering for D depth profiling}

In a recent publication we have shown that the resolution for $\mathrm{D}$ depth profiling can be significantly improved compared to standard NRA by consecutive low-energy argon plasma sputtering followed by ion beam analysis [13]. For this reason, low-energy Ar plasma sputtering was also performed in PlaQ for samples exposed to a $\mathrm{D}$ fluence of $1.0 \times 10^{24} \mathrm{D} / \mathrm{m}^{2}$ from the aforesaid three groups. The Ar pressure was $0.5 \mathrm{~Pa}$ and the applied DC bias voltage $-200 \mathrm{~V}$. To reduce the implantation of impurities from the Ar plasma due to venting, 15-min plasma burn-in was also performed until the chamber cleaned itself. Before applying the DC bias, all samples were exposed to Ar plasma at floating potential ( $3 \mathrm{~V}$ ) for $10 \mathrm{~min}$ to gently remove adsorbed impurities. To reduce a possible D loss during sputtering the sample temperature was kept at $230 \mathrm{~K}$ using the ethanol cooling circuit. To ensure a thorough comparison of D retention and a detailed reconstruction of the $\mathrm{D}$ depth profiles, different durations of Ar-plasma exposure on different sections of the identical sample were performed by partially covering the sample surface with a 50 micron thick W foil while keeping other parts exposed to Ar plasma. Because the sputtering experiments on different areas of the sample cannot be performed within one Ar plasma exposure, the chamber had to be opened for rearranging the tungsten-foil cover several times. For example, to produce four sectors on one sample with Ar exposure times of 5, 10, 20 and 25 min we first covered one half of a D-implanted sample with the tungsten foil and exposed the uncovered half to Ar plasma for 15 min. Then for the second Ar plasma exposure we rotated the foil by 90 degrees thus covering the perpendicular half of the sample. That means one quarter of the sample that was previously covered and another quarter that was previously sputtered for 15 min were exposed in the second, 5 min long Ar plasma exposure thus producing areas that in total experienced Ar sputtering for 5 and $20 \mathrm{~min}$. In the final step this sample was exposed to Ar plasma without

W-foil cover for additional 5 min such that this sample had four different quarters which were exposed to 
Ar plasma for 5, 10, 20 and $25 \mathrm{~min}$. Another identical sample was exposed similarly as the first sample, but with 15 min intervals thus producing a sample with 0, 15, 30, and 45 min Ar plasma exposure. Finally, 8 areas with different Ar sputtering durations were produced on 2 identical samples, namely 7 areas from 0 to $30 \mathrm{~min}$ with $5 \mathrm{~min}$ sputtering intervals and additionally one area with $45 \mathrm{~min}$ Ar sputtering.

After low-energy Ar sputtering of different durations the corresponding sections of the sample surfaces were further characterized by NRA and RBS for the remaining D amount and $\mathrm{WN}_{\mathrm{x}}$ layer thickness, respectively. Based on this, the amount of sputtered $\mathrm{WNx}$ layer and the removed $\mathrm{D}$ amount can be determined. Combining the experimental results from RBS and NRA, the depth distributions of D in the top-most surface were reconstructed with a resolution of $\sim 3 \mathrm{~nm}$ which is more than 5 times better than the resolution obtained by analyzing the alpha signal.

\subsection{Thermal release of $D$ from $W N x$ by $T P D$}

After the NRA measurements the released D amounts of several selected samples were measured by TPD in TESS (see Sect. 2.2). Additional mass channels were traced in these experiments. Besides mass channels $2\left(\mathrm{H}_{2}\right), 3(\mathrm{HD})$ and $4\left(\mathrm{D}_{2}\right)$, mass channels $18\left(\mathrm{NH}_{2} \mathrm{D}\right), 19\left(\mathrm{NHD}_{2}\right)$ and $20\left(\mathrm{ND}_{3}\right)$ were also included to monitor the possible release of deuterated ammonia. The calibration for $\mathrm{D}_{2}$ and $\mathrm{HD}$ was done similarly as for $\mathrm{N}_{2}$ and the determined calibration factors were $4.1 \times 10^{8} \mathrm{D}_{2}$ - and $4.2 \times 10^{8} \mathrm{HD}$-molecules per count, respectively. The calibration of deuterated ammonia, however, was not possible. On the one hand, ammonia sticks strongly to the chamber wall such that the introduction of large amounts of ammonia for calibration would pollute the whole TESS device. On the other hand, the same mass of different deuterated ammonia and water isotopologues (18 amu for both $\mathrm{NH}_{2} \mathrm{D}$ and $\mathrm{H}_{2} \mathrm{O}, 19$ amu for $\mathrm{NHD}_{2}$ and $\mathrm{HDO}$ and 20 amu for $\mathrm{ND}_{3}$ and $\mathrm{D}_{2} \mathrm{O}$ ) cannot be distinguished with a standard low-mass-resolution QMS. Hence, the total amount of D released in form of hydrogen molecules was calculated from the integral of the $\mathrm{D}_{2}(4 \mathrm{amu})$ and $\mathrm{HD}(3 \mathrm{amu})$ peaks. It has to be stressed that this is only a lower limit to the retained D amount in the samples for two reasons: Firstly, some of the D in the layers is released in form of water and ammonia which cannot be quantified as discussed above, Secondly, because the layers completely delaminated from the substrate because of the TPD analysis we could not check whether some D still remains in the layers.

\section{Characterization of the WNx layer}

$\mathrm{WN}_{\mathrm{x}}$ layers were characterized with RBS for the initial areal density as well as the $\mathrm{N}$ amount and concentration. Fig. 2a shows a full RBS spectrum (measured with $1500 \mathrm{keV}^{4} \mathrm{He}^{+}$) of as-deposited $\mathrm{WN}_{\mathrm{x}}$ layer sample exposed to $\mathrm{D}$ fluence of $1.0 \times 10^{24} \mathrm{D} / \mathrm{m}^{2}$ prior to Ar sputtering. For comparison the simulated RBS spectrum of a W film without $\mathrm{WN}_{\mathrm{x}}$ coating is also shown as a dashed line in the figure. The measured data is represented by symbol and the corresponding SIMNRA [20] simulation by solid line. The simulated spectrum does not fit very well to the experimental data at low backscattering energy. This can be explained by the large uncertainty of the stopping power and cross-section data at low projectile energies. However, in the relevant energy range $(\mathrm{E}>1000 \mathrm{keV})$ the simulated spectrum fits the experimental data very well. The relevant information from the near surface region appears in the backscatter energy range from about 1200 to $1400 \mathrm{keV}$. This region is enlarged as the inset of Fig. 2a. The W concentration within the coating - corresponding to the RBS signal from the high energy edge at about $1370 \mathrm{keV}$ to the interface to the pure $\mathrm{W}$ layer located at about $1220 \mathrm{keV}$ - is lower than for the $\mathrm{W}$ substrate because of the presence of nitrogen. The step located at about $1220 \mathrm{keV}$ marks the transition from the $\mathrm{WN}_{\mathrm{x}}$ layer to the underlying $\mathrm{W}$ film. Without $\mathrm{WN}_{\mathrm{x}}$ coating, as shown by the spectrum of pure W no such step appears. The width of the Wdepleted region in the RBS spectra corresponds to the areal density of the $\mathrm{WN}_{\mathrm{x}}$ layer and the height of the RBS signal at a specific energy depends on the local $\mathrm{W}$ concentration. The RBS signal of the $\mathrm{N}$ species in 
the $\mathrm{WN}_{\mathrm{x}}$ layer, which should appear in the backscattering energy range of 350-480 keV, cannot be directly seen due to the intense $\mathrm{W}$ signal and the low cross section for $\mathrm{N}$. However, the $\mathrm{N}$ concentration in the $\mathrm{WN}_{\mathrm{x}}$ layers can be derived from a simulation of high energy part of the RBS spectrum by SIMNRA [20]. Adding nitrogen to the W-depleted zone within SIMNRA one can fit the experimental curve. The assumption that $\mathrm{N}$ is the only species that dilutes $\mathrm{W}$ in this layer is valid as the oxygen and carbon content is less than $1 \%$ as measured with XPS. Since Ar is used as working gas during film deposition, the samples were also checked for their Ar content. Neither RBS nor XPS resulted in a measurable Ar content, but the sensitivity for both methods is only of the order of $1 \%$, meaning that smaller concentrations cannot be detected. During TPD we found a small signal on mass 40 which is attributed to Ar. But since the integral of the mass 40 peak is about 2 orders of magnitude lower than the $\mathrm{N}_{2}$-related peak at mass 28 and since the $\mathrm{Ar}$ is most probably also contained in the much thicker $\mathrm{W}$ interlayer, the $\mathrm{Ar}$ content in the $\mathrm{WN}_{\mathrm{x}}$ layer is estimated to be much lower than $10^{-2}$ and, therefore, considered to be negligible.
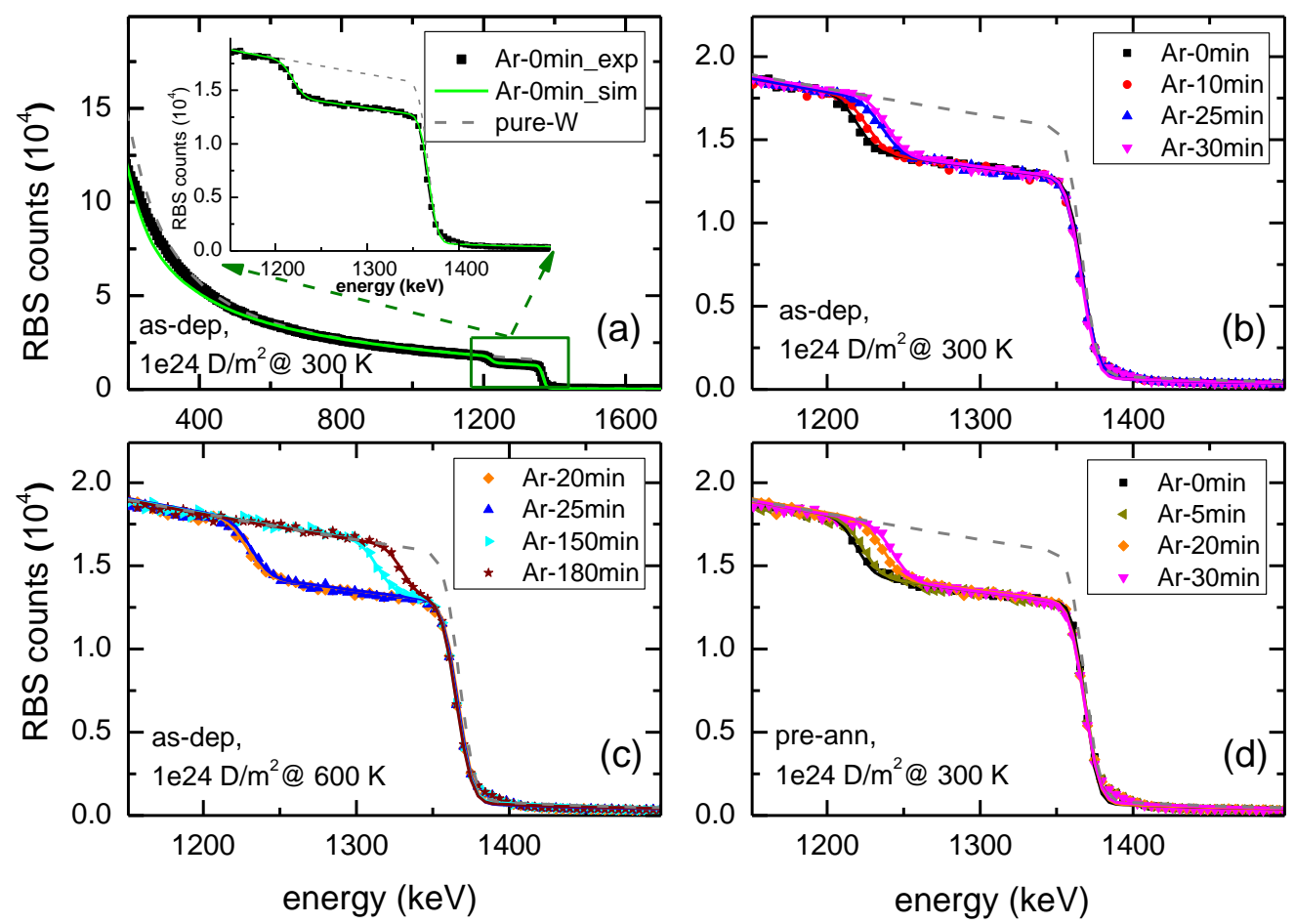

Fig. 2: RBS spectra of magnetron-sputtered WN $N_{x}$ films (deposited on Si substrates pre-coated with a $2 \mu m$ thick W film) after D plasma exposure at 300 and $600 \mathrm{~K}$ and after different Ar sputtering times (sputtering times are indicated in the figure): a) full RBS spectrum of an as-deposited sample exposed to D plasma at $300 \mathrm{~K} ; \mathrm{b}$ ) enlarged view of the informational part (as indicated by the dashed box in (a)) from as-deposited samples exposed at $300 \mathrm{~K} ; \mathrm{c}$ ) as-deposited samples exposed at $600 \mathrm{~K} ; \mathrm{d}$ ) samples annealed for $2 \mathrm{~h}$ at $600 \mathrm{~K}$ and exposed at $300 \mathrm{~K}$. In all subfigures symbols represent experimental data and solid lines SIMNRA simulation results (for details see text).

As a result of that fitting procedure a $\mathrm{W}$ concentration in the $\mathrm{WN}_{\mathrm{x}}$ layer of $(56 \pm 2) \%$ is deduced. The measured areal density of the as-deposited layer before D implantation is $1.0 \times 10^{22}$ atoms $/ \mathrm{m}^{2}$ and after D exposure with fluence of $1.0 \times 10^{24} \mathrm{D} / \mathrm{m}^{2}$ it is $9.4 \times 10^{21}$ atoms $/ \mathrm{m}^{2}$. Obviously, $6.0 \times 10^{20}$ atoms $/ \mathrm{m}^{2} \mathrm{WN}_{\mathrm{x}}$ layer had been removed by the $\mathrm{D}$ implantation. Together with the initial thickness measurement of the deposited film $\left(135 \pm 5 \mathrm{~nm}\right.$, see Sect. 2.1), we can determine the atom number density of our $\mathrm{WN}_{\mathrm{x}}$ layer. It is roughly $7.4 \times 10^{28}$ atoms $/ \mathrm{m}^{3}$. Based on this density, we can calculate from the RBS data the removed layer thicknesses by each sputtering step for later used D depth profiling. 


\section{D retention in $W N x$}

\subsection{D depth profiles}

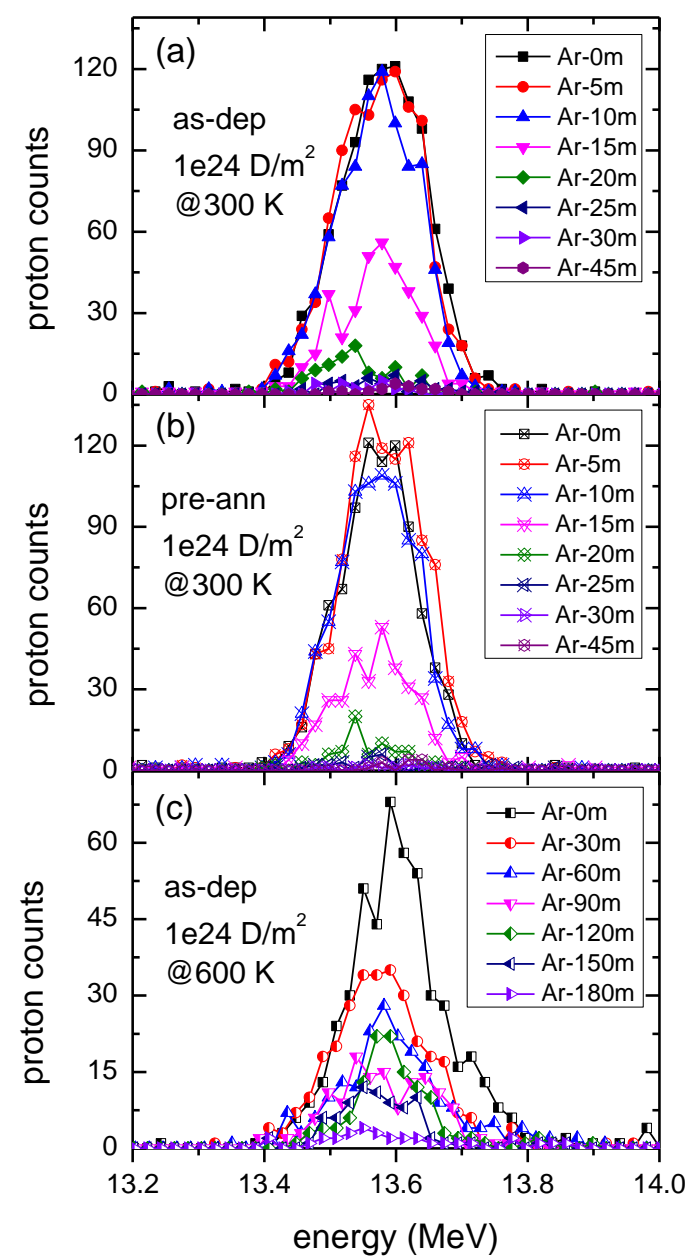

Fig. 3: NRA proton peaks of samples from Fig 2.

As mentioned above, D plasma exposure of $\mathrm{WN}_{\mathrm{x}}$ layers was performed for three different cases: a) asdeposited layers exposed at $300 \mathrm{~K}, \mathrm{~b}$ ) as-deposited layers exposed at $600 \mathrm{~K}$ and c) layers annealed prior to exposure for $2 \mathrm{~h}$ at $600 \mathrm{~K}$ and then exposed at $300 \mathrm{~K}$. From each of these cases, the sample that was exposed to a $\mathrm{D}$ fluence of $1.0 \times 10^{24} \mathrm{D} / \mathrm{m}^{2}$ was selected for low-energy Ar sputtering for D depth profiling (see Sect. 2.5). Samples with $\mathrm{WN}_{\mathrm{x}}$ coatings after different Ar sputtering times are presented in Figs. $2 \mathrm{~b}$ to d. Note that, only the interesting near surface regions (1200-1400 keV) were shown. As anticipated, the area without Ar sputtering shows always the thickest $\mathrm{WN}_{\mathrm{x}}$ layer. With increasing sputtering time the edge of the pure $\mathrm{W}$ interlayer shifts to higher backscattering energies indicating the decrease of the thickness of the $\mathrm{WN}_{\mathrm{x}}$ layer on top. For clarity, only selected RBS spectra are shown in Figs. 2b-d, because a 5-min Ar sputtering step removes only a very small amount of $\mathrm{WN}_{\mathrm{x}}$. One RBS spectrum shown in Fig. 2c stems from an area after 180-min Ar sputtering. In this case the shift of the pure-W edge is most pronounced and the thickness of the remaining $\mathrm{WN}_{\mathrm{x}}$ layer is only about $40 \mathrm{~nm}$. The amount of sputtered $\mathrm{WN}_{\mathrm{x}}$ was determined by fitting the RBS spectra with SIMNRA assuming constant $\mathrm{N}$ concentration throughout the WNx films (no $\mathrm{W}$ enrichment within the Ar ion range). The RBS spectra in Figs. $2 b$ and d look very similar to each 
other. This indicates that the pre-annealing had little or no influence on the layer stoichiometry and on the sputtering yield of these $\mathrm{WN}_{\mathrm{x}}$ films. Each 5-min Ar sputtering interval removes about $3.2 \mathrm{~nm} \mathrm{WN}_{\mathrm{x}}$ layer for both as-deposited and pre-annealed samples. However, for the samples exposed at $600 \mathrm{~K}$ (Fig. 2c) each 5 min Ar sputtering interval removes only about $2.7 \mathrm{~nm}$ in average.

Fig. 3 shows the proton spectra from the nuclear reaction of $\mathrm{D}\left({ }^{3} \mathrm{He}, \mathrm{p}\right) \alpha$ with a $500 \mathrm{keV}{ }^{3} \mathrm{He}^{+}$ion beam after different Ar sputtering durations. In general, the proton yields, corresponding to the $\mathrm{D}$ amount remaining in the $\mathrm{WN}_{\mathrm{x}}$ layer, decreases with the increasing Ar sputtering time. For both as-deposited (Fig. 3a) and pre-annealed (Fig. 3b) samples exposed to D plasma at $300 \mathrm{~K} 30 \mathrm{~min}$ Ar plasma sputtering is sufficient to almost completely remove the D-containing layer indicated by the disappearance of the proton signal. The sample exposed at $600 \mathrm{~K}$ differs in two regards: First, the initial proton signal is only about half of that as for $300 \mathrm{~K}$ exposure and, second, it takes much longer to remove the D-containing layer. It turned out that the proton peak disappeared only after $180 \mathrm{~min}$ Ar sputtering. However, the 5-min-Ar sputtered area of the pre-annealed sample (Fig. 3b) shows surprisingly a larger proton peak than that from the area without Ar sputtering. The reason for this deviation is unclear. Most probably it is due to an experimental outlier because the proton peak integral of the pre-annealed sample is also lower than for the as-deposited sample while all other proton spectra for these two samples agree. In any case, other data points show the expected decreasing behavior. Although this ambiguity is unsatisfactory it has no influence on the further evaluation of the data. According to the thickness calculation based on the RBS-determined atom density of our layers as discussed above, after $30 \mathrm{~min}$ Ar sputtering of the $300 \mathrm{~K}$ exposed sample about $19 \mathrm{~nm} \mathrm{WN}$ is removed and $180 \mathrm{~min}$ sputtering of the $600 \mathrm{~K}$ exposed sample corresponds to about $100 \mathrm{~nm}$. In all shown cases, the D-containing layers are much thinner than the information depth of the applied NRA measurements with a $500 \mathrm{keV}$ projectile energy $(\sim 680 \mathrm{~nm}$, see Sect. 2.5). From the disappearance of the proton peaks we conclude that for the here used D fluence of $1.0 \times 10^{24} \mathrm{D} / \mathrm{m}^{2}$ all $\mathrm{D}$ was retained in $\mathrm{WN}_{\mathrm{x}}$ layer thicknesses of $19 \mathrm{~nm}$ for $300 \mathrm{~K}$ exposed samples and $\sim 100 \mathrm{~nm}$ for samples exposed at $600 \mathrm{~K}$.

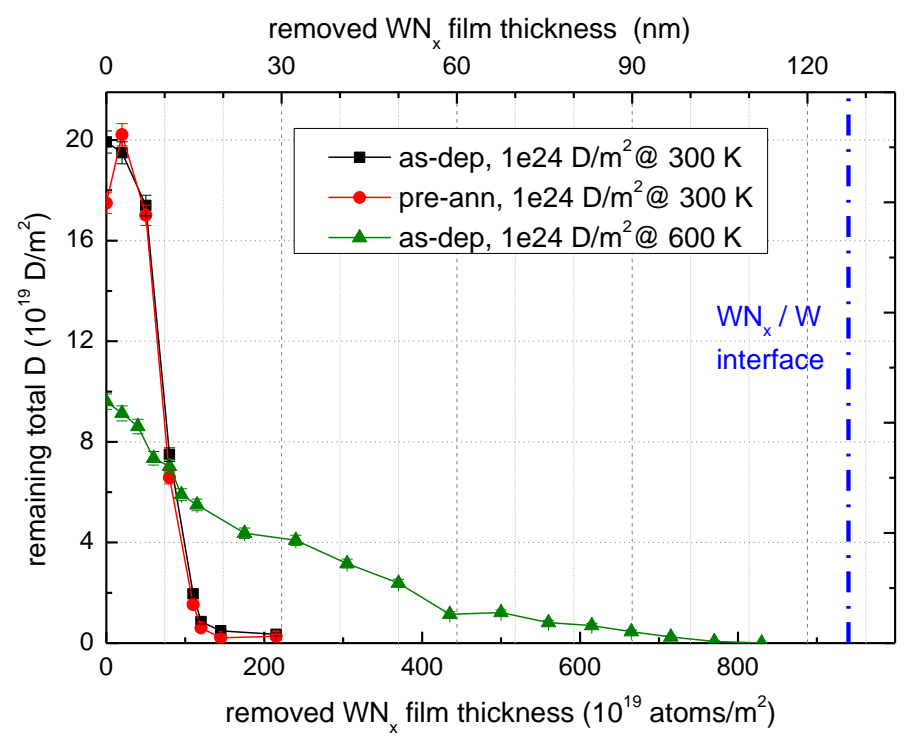

Fig. 4: Total D amount in $W N_{x}$ samples exposed to $1 \times 10^{24} \mathrm{D} / \mathrm{m}^{2}$ at $-200 \mathrm{~V}$ bias after different Ar plasma exposure durations. The lower scale shows the removed $W N_{x}$ layer thickness in units of atoms $/ \mathrm{m}^{2}$; the initial film thickness is about $9.4 \times 10^{21}$ atoms $/ \mathrm{m}^{2}$. The upper scale is a thickness scale in nanometers calculated using a WN density of $7.4 \times 10^{28}$ atoms $/ \mathrm{m}^{3}$. The approximate position of the $W N_{x} / W$ interface is also indicated. 
Based on the experimentally measured cross-section data from Alimov [19], the amounts of retained D in the remaining $\mathrm{WN}_{\mathrm{x}}$ layers after each Ar sputtering step are calculated. The total D amounts determined from the proton signals are shown in Fig. 4 as a function of the removed $\mathrm{WN}_{\mathrm{x}}$ layer thickness. The removed amount of $\mathrm{WN}_{\mathrm{x}}$ layer is shown in units of atom areal density in the bottom x-scale and in ' $\mathrm{nm}$ ' in the top $\mathrm{x}$-scale of Fig. 4. The thickness scale is only indicative and was calculated using the determined atom density as discussed further above. The total $\mathrm{D}$ amounts remaining in the $\mathrm{WN}_{\mathrm{x}}$ layers exposed at $300 \mathrm{~K}$ decrease very fast with Ar sputtering time. For exposure at $300 \mathrm{~K}$ more than $97 \%$ of the $\mathrm{D}$ in the sample was retained in a 16-nm-thick WN layer. The non-linear decrease is most probably a consequence of an inhomogeneous D depth distribution. For the sample exposed at $600 \mathrm{~K}$, the initially retained D amount before Ar sputtering is half of that at $300 \mathrm{~K}$ and the decreases with increasing Ar sputtering time is significantly slower than that at $300 \mathrm{~K}$. Due to the lower total retained D amount and its larger penetration depth the local D concentration at $600 \mathrm{~K}$ is much lower than at $300 \mathrm{~K}$.

On the basis of the total D amount remaining after sputtering as presented in Fig. 4 and the removed $\mathrm{WN}_{\mathrm{x}}$ layer measured by RBS (Fig. 2) the D depth profiles in the $\mathrm{WN}_{\mathrm{x}}$ layer can be determined. Thereby we assume that $\mathrm{D}$ is distributed uniformly within the removed $\mathrm{WN}_{\mathrm{x}}$ layer from each sputtering step. The resulting D depth profiles of as-deposited samples exposed at $300 \mathrm{~K}$ and $600 \mathrm{~K}$ are shown in Fig. 5. The depth profile for the pre-annealed sample is not plotted because it is almost identical to that of the asdeposited sample.

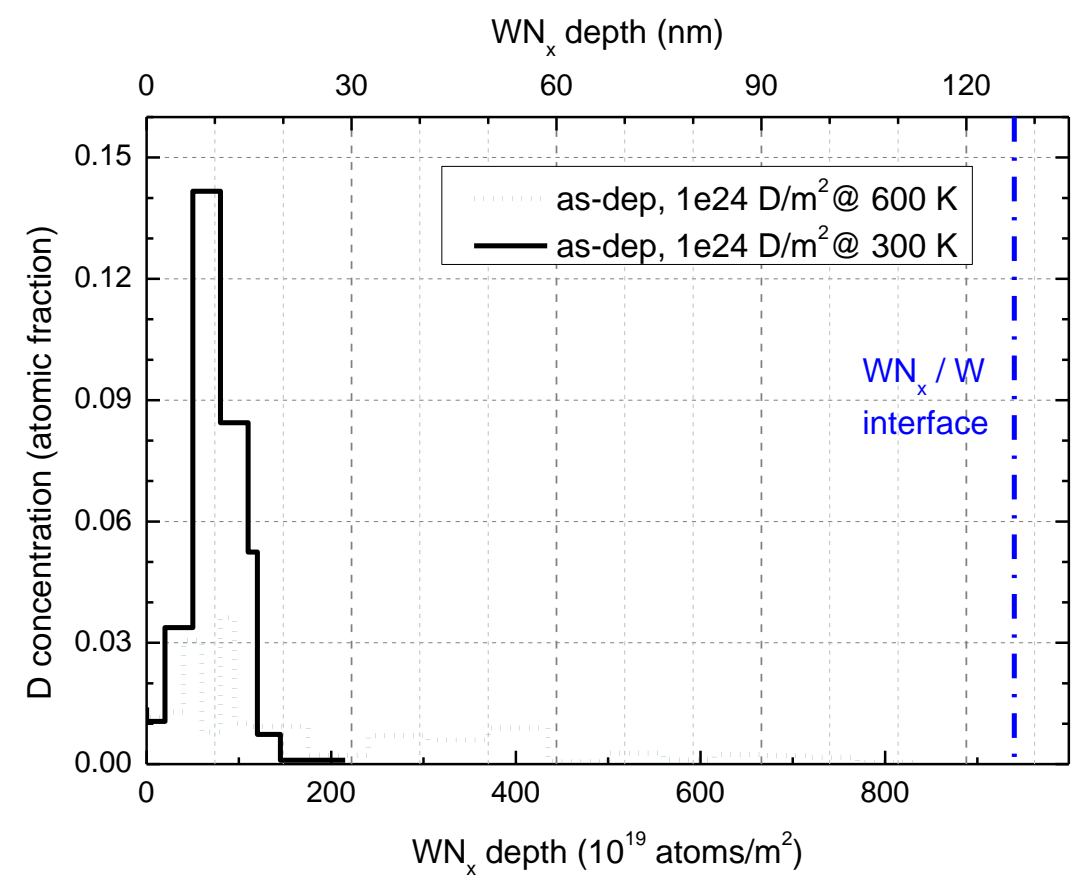

Fig. 5: Experimentally measured D depth profiles in $W N_{x}$ samples after $1 \times 10^{24} \mathrm{D} / \mathrm{m}^{2}$ implantation. Note that the lower and upper $x$-scales are shown in different units. The upper scale is a thickness scale in nanometers calculated using a WN density of $7.4 \times 10^{28}$ atoms $/ \mathrm{m}^{3}$.

As one can see in Fig. 5, at $300 \mathrm{~K}$, the $\mathrm{D}$ in the $\mathrm{WN}_{\mathrm{x}}$ layer first increases with increasing depth, reaches its peak concentration of about 14 at. $\%$ in a depth of 7-11 nm and then drops quickly to 1 at. $\%$ at $\sim 16 \mathrm{~nm}$. At larger depth, the D concentration is below 1 at. $\%$ and no $\mathrm{D}$ is detected beyond a depth of $19 \mathrm{~nm}$. For D implantation at $600 \mathrm{~K}$, the peak concentration is only about 3 at. \% in a depth up to $14 \mathrm{~nm}$, which is a factor of 5 lower than that of the $300 \mathrm{~K}$-implanted samples. However, the D concentration remains at a level of a 
few atomic percent up to depth of $\sim 60 \mathrm{~nm}$. For larger depth the D concentration further decreases and no D is detected for a depth larger than $110 \mathrm{~nm}$.

SDTrimSP [21, 22] simulations of D implantation were performed to interpret the present experimental results. The same W:N ratio as determined by RBS for our deposited layers was set as target matrix in the simulation. In total $10^{9}$ projectiles were simulated, the cutoff energy of the projectiles was set to $2 \mathrm{eV}$ and the target was discretized into layers with $0.4 \mathrm{~nm}$ thickness. The simulations were performed for normal impact angle and an energy distribution corresponding to a $\mathrm{D}$ flux consisting predominantly from $\mathrm{D}_{3}{ }^{+}$ions (94\%) and minority contributions of $\mathrm{D}^{+}(3 \%)$ and $\mathrm{D}_{2}{ }^{+}$ions $(3 \%)$. The molecular ions are treated as individual deuterons impinging with the same velocity. For example, a $\mathrm{D}_{3}{ }^{+}$ion with energy of $215 \mathrm{eV}$, as in the present case, will be treated as three impinging deuterons with energy of $72 \mathrm{eV}$ and a $\mathrm{D}_{2}{ }^{+}$corresponds to two deuterons with energy of $108 \mathrm{eV}$. The simulated $\mathrm{D}$ implantation depth distributions for the fixed ion energy of $215 \mathrm{eV}$ resulting in three different energies per deuteron as just explained are plotted in Fig. 6. The simulations were performed in static mode, that means the possible retention of $\mathrm{D}$ in the matrix as well as preferential erosion of $\mathrm{N}$ from the matrix were not taken into account, or with other words each $\mathrm{D}$ impinged on the pure, D-free W:N matrix.

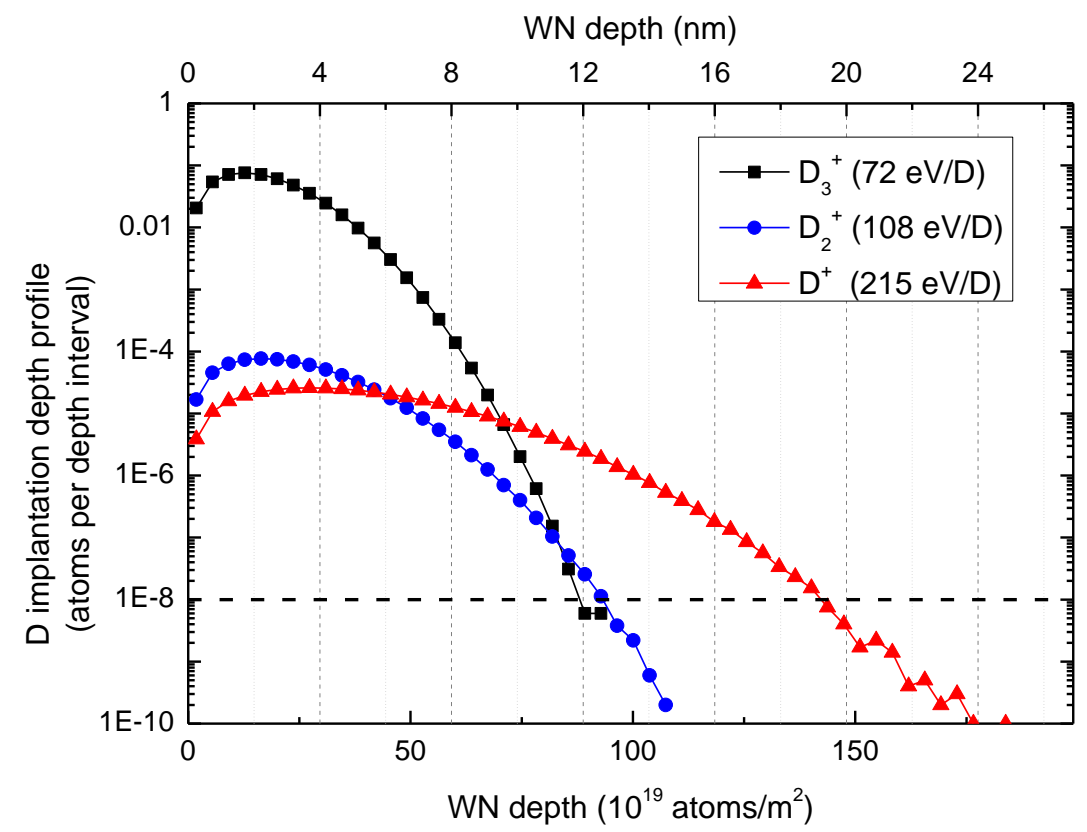

Fig. 6: SDTrimSP simulation of the distribution of implanted deuterons in WN matrix. Plotted is the probability to find an impinging deuteron in the given depth in a depth interval of $0.4 \mathrm{~nm}$. The total incident amount of $D$ is $10^{9}$. The reflection coefficient is roughly 0.5 (for details see text). The lower $x$-scale shows the layer thickness in units of areal density (atoms per $m^{2}$ ); the upper $x$-axis shows a thickness scale in nanometers calculated using a WN density of $7.4 \times 10^{28}$ atoms $/ \mathrm{m}^{3}$.

Before interpreting the simulation results it is advisable to recall what SDTrimSP can simulate and what not. TRIM and related simulation tools describe the transport of energetic ions in matter on the basis of the binary collision approximation. In our case, the results presented in Fig. 6 describe how far an energetic particle penetrates into the matrix material before its kinetic energy drops below $2 \mathrm{eV}$. SDTrimSP cannot describe what happens with the particle after it has lost its kinetic energy. In particular, it cannot describe the possible diffusion of a thermalized species. That means Fig. 6 shows the penetration probability distribution (range distribution) of the $\mathrm{D}$ species mix according to the species composition of our plasma 
impinging on a $\mathrm{WN}_{\mathrm{x}}$ layer. The deuterons impinging in form of $\mathrm{D}_{3}{ }^{+}$ions are shown by the diamonds in Fig. 6. Since their contribution to the total flux is highest the probability to find them in the layer is also largest. But with the lowest energy per deuteron, their penetration depth is also smallest. The deuterons impinging in form of $\mathrm{D}_{2}{ }^{+}$ions (circles) have a somewhat higher energy and a much lower intensity. Due to the slightly higher energy than the deuterons impinging in form of $\mathrm{D}_{3}{ }^{+}$they penetrate slightly deeper. Finally, deuterons impinging as atomic ions (triangles) have an even lower probability but a significantly higher penetration depth. If we take quite arbitrarily a level of $10^{-8}$ in Fig. 6 as cutoff the penetration depths for the three different ion species are about 12, 13 and $19 \mathrm{~nm}$, respectively. In addition to penetration SDTrimSP also yields the reflection coefficient. The reflection coefficients for the three different energies per deuteron considered here $-72,108$, and $215 \mathrm{eV}$ per D - are $0.49,0.47$, and 0.45 , respectively. That means that about $50 \%$ of the impinging deuterons do not enter the layer but are kinetically reflected out of the sample surface. It is interesting to note that the corresponding reflection yields for pure $\mathrm{W}$ surface are $0.67,0.65$ and 0.62 , respectively. That means the presence of $\mathrm{N}$ in the surface reduces the reflection yield.

Comparing the D implantation ranges estimated from Fig. 6 with the experimentally determined D depth distribution for D implantation at $300 \mathrm{~K}$ (Fig. 5) we find that the thickness of the D-containing layer (about $20 \mathrm{~nm}$ ) can be solely explained by implantation. It agrees very well with the penetration range of the $\mathrm{D}$ species with the highest energy per $\mathrm{D}$ stemming from the small fraction of atomic D ions which impinge with the maximum energy of $215 \mathrm{eV}$. At $600 \mathrm{~K}$, the measured D-containing layer is much thicker ( 100 nm) than the calculated implantation ranges. We attribute this to diffusion of implanted deuterons. Therefore, we conclude that at $300 \mathrm{~K} \mathrm{D}$ implanted into $\mathrm{WN}_{\mathrm{x}}$ remains in the implantation zone and does not diffuse into larger depth, while at $600 \mathrm{~K} \mathrm{D}$ will-after thermalization-diffuse. Obviously, the onset temperature for $\mathrm{D}$ diffusion in $\mathrm{WN}_{\mathrm{x}}$ lies between 300 and $600 \mathrm{~K}$. Further experiments for determining this onset temperature are planned. Even though diffusion plays obviously a role on the final D depth distribution at $600 \mathrm{~K}$, it should be emphasized that for the chosen experimental conditions all the retained $\mathrm{D}$ is found within the deposited $135 \mathrm{~nm}$ thick $\mathrm{WN}_{\mathrm{x}}$ layer and does not reach the underlying $\mathrm{W}$ film (as indicated by the W/WN interface in Figs. 4\&5) substrate. For comparable implantation conditions in bulk, polycrystalline W D would penetrate much deeper and reach depths several micrometers. A direct comparison with D retention in bulk W is difficult, because the latter is strongly dependent on the experimental parameters [23]. For higher implantation energy ( $200 \mathrm{eV} / \mathrm{D})$ but comparable exposure temperature $(573 \mathrm{~K}) \mathrm{D}$ penetrates more than $6 \mu \mathrm{m}$ [23]. On the other hand, even at lower implantation energy ( $38 \mathrm{eV} / \mathrm{D})$ and lower exposure temperature $(300 \mathrm{~K}) \mathrm{D}$ penetrates more than $6 \mu \mathrm{m}$ [24]. But in both cases the measured D concentrations are significantly lower than in the $\mathrm{WN}_{\mathrm{x}}$ films investigated here. It is further interesting to note that $\mathrm{D}$ retention in magnetron sputtered films shows a different behavior than in bulk W. A homogeneous filling of magnetron sputtered $\mathrm{W}$ films with thicknesses up to $12 \mu \mathrm{m}$ was reported by Wang et al. (exposure conditions: $38 \mathrm{eV} / \mathrm{D}, 370 \mathrm{~K}$, D fluence $6 \times 10^{24} \mathrm{Dm}^{2}$ ) [14, 25]. From the comparison of the here measured penetration depth with these literature values we conclude that the diffusivity of $\mathrm{D}$ in our $\mathrm{WN}_{\mathrm{x}}$ layer is significantly lower than that in bulk or magnetron-sputtered pure W.

\subsection{Total retained $D$ amount by $N R A$}

In addition to the implanted $\mathrm{D}$ fluence of $1.0 \times 10^{24} \mathrm{D} / \mathrm{m}^{2}$ presented above a $\mathrm{D}$ fluence scan was conducted for the three different sample batches. Fig. 7 shows the total amount of retained D for the three different investigated cases as deduced from the proton counts as described before for a $\mathrm{D}$ fluence range between $1.0 \times 10^{23} \mathrm{D} / \mathrm{m}^{2}$ and $6.0 \times 10^{24} \mathrm{D} / \mathrm{m}^{2}$. For each set of $\mathrm{D}$ fluences the $\mathrm{D}$ amount in as-deposited $\mathrm{WN}_{\mathrm{x}}$ exposed at $300 \mathrm{~K}$ is always the highest. The pre-annealed samples show a very similar but slightly (10 to $15 \%)$ lower D retention. Samples exposed at $600 \mathrm{~K}$ retain only about half of the amount as the 300-Kexposed samples. At $300 \mathrm{~K}$ even for the lowest investigated fluence of $1.0 \times 10^{23} \mathrm{D} / \mathrm{m}^{2}$ the retained $\mathrm{D}$ amount 
corresponds already to $75 \%$ of the retained D amount measured for the 10-times higher fluence. For fluences higher than $1.0 \times 10^{24} \mathrm{D} / \mathrm{m}^{2}$ the trend is not very clear. The as-deposited sample shows a slight further increase by about $10 \%$, while the $\mathrm{D}$ content in the pre-annealed sample is practically constant in this range. Surprisingly, at low D fluence $\left(\leq 5.0 \times 10^{23} \mathrm{D} / \mathrm{m}^{2}\right)$, the total retained $\mathrm{D}$ amounts from both sets of 300-K-implanted samples first decrease slightly and only then increase with D fluence. Although not easy to understand, this behavior turned out to be reproducible in additional independent experiments. A possible reason for this will be discussed later. The sample exposed at $600 \mathrm{~K}$ shows only negligible fluence dependence. The $\mathrm{D}$ amount increases by less than $10 \%$ over the whole investigated fluence range. One point worthy to mention is the fraction of the retained $\mathrm{D}$ amount compared with the impinging $\mathrm{D}$ fluence. Presently, for all 3 sets of samples up to the highest impinging D fluence $\left(6 \times 10^{24} \mathrm{D} / \mathrm{m}^{2}\right)$, the total retained amount is below $2.5 \times 10^{20} \mathrm{D} / \mathrm{m}^{2}$. The fraction of retained $\mathrm{D}$ normalized to the incoming $\mathrm{D}$ fluence at this highest fluence is roughly $4 \times 10^{-4}$ at $300 \mathrm{~K}$ and $2 \times 10^{-4}$ at $600 \mathrm{~K}$. Even at the lowest fluence $\left(1 \times 10^{23} \mathrm{D} / \mathrm{m}^{2}\right)$, the retained fraction is still below $2 \times 10^{-3}$ at $300 \mathrm{~K}$ and roughly $1 \times 10^{-3}$ at $600 \mathrm{~K}$. The retained fractions are even a factor of 10 or 100 lower than the contribution from the minority ion species $\mathrm{D}^{+}$which contributes $1 \%$ to the total impinging $\mathrm{D}$ flux. In this respect it should also be kept in mind that, as discussed above, about $50 \%$ of the impinging deuterons do not enter the film, but are reflected directly at the surface.

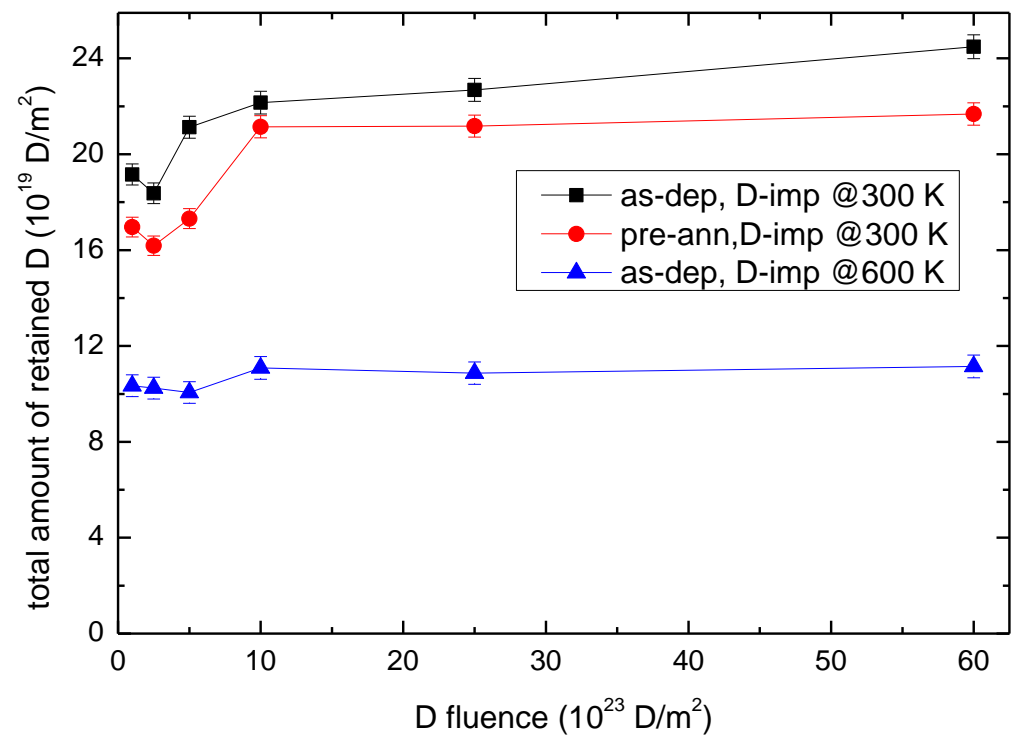

Fig. 7: Total amount of retained $D$ in $W N_{x}$ samples (measured by NRA) as function of $D$ fluence.

\subsection{D release from $W N x: T P D$}

Samples exposed to the highest D fluence of $6 \times 10^{24} \mathrm{D} / \mathrm{m}^{2}$ were investigated with TPD measurements. The TPD spectra of $\mathrm{D}$ released in form of $\mathrm{D}_{2}$ (signal mass channel 4) and $\mathrm{HD}$ (signal mass channel 3) are shown in Figs. $8 \mathrm{a}$ and b, respectively. As one can see in the figure, the release of both $\mathrm{D}_{2}$ and $\mathrm{HD}$ from the samples exposed to $\mathrm{D}$ plasma at $300 \mathrm{~K}$ sets in at $\mathrm{T} \approx 370 \mathrm{~K}$. In all these cases the release spectrum is composed of 2 release peaks located at about 440 and $520 \mathrm{~K}$. For both species the second peak is lower for the TPD spectrum of the pre-annealed sample. For the sample exposed at $600 \mathrm{~K}, \mathrm{D}_{2}$ release sets in at roughly $500 \mathrm{~K}$ and peaks at $\sim 650 \mathrm{~K}$. It is interesting to note that the starting temperature is lower than the implantation temperature. This is normally not the case for D implantation into pure $\mathrm{W}[14,24,25]$, where the $\mathrm{D}$ release only starts at a temperature very close to the implantation temperature. The $\mathrm{N}_{2}$ release from 
these D-exposed $\mathrm{WN}_{\mathrm{x}}$ layers was also measured, but it is not plotted in Fig. 8 because of its 2 orders of magnitude higher release rate compared with the $\mathrm{D}_{2}$ release. Similarly as the reduced $\mathrm{WN}_{\mathrm{x}}$ films in Fig. 1 , $\mathrm{N}_{2}$ release in $\mathrm{WN}_{\mathrm{x}}$ after $\mathrm{D}$ implantation starts only at $\mathrm{T} \geq 830 \mathrm{~K}$ when release of $\mathrm{D}_{2}$ and HD has almost ceased. The released $\mathrm{N}$ amount determined from the analysis of the $\mathrm{N}_{2}$ release peak at $28 \mathrm{amu} / \mathrm{q}$ for each of the three samples after D implantation is determined (about $4.7 \times 10^{21} \mathrm{~N} / \mathrm{m}^{2}$ ) and compared with that prior to D implantation. Unfortunately, the TPD spectrum prior to D implantation was measured using a sample from a different $\mathrm{WN}_{\mathrm{x}}$ deposition batch than the TPD spectrum of the sample after D implantation, such that small differences in the $\mathrm{N}$ concentration or $\mathrm{WN}_{\mathrm{x}}$ layer thickness could lead to small differences in the total $\mathrm{N}$ amount. Due to this uncertainty we can at present not make a quantitative comparison. Nevertheless, from the analysis of the $\mathrm{N}_{2}$ release spectrum we can state that the amount of $\mathrm{N}$ released in form of $\mathrm{N}_{2}$ is comparable to the $\mathrm{N}$ amount measured by RBS.

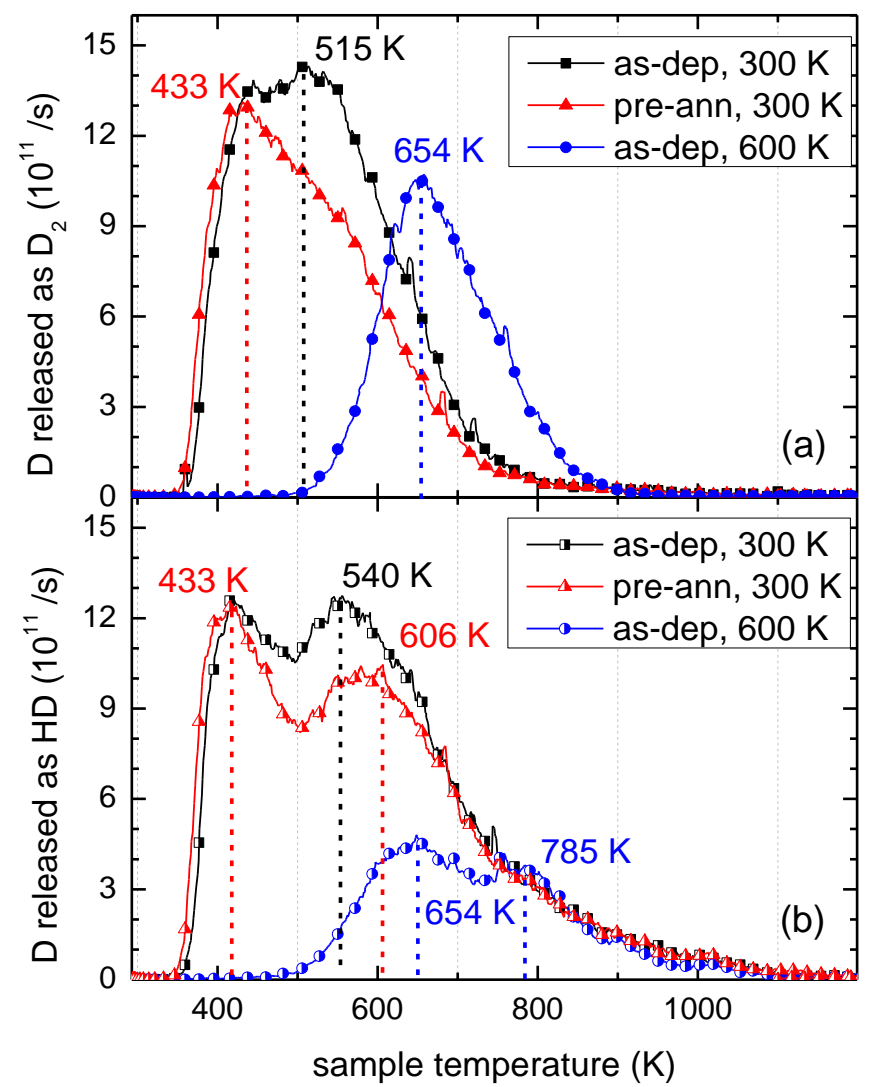

Fig. 8: D release spectra from $W N_{x}$ samples after exposure with $D$ fluence of $6 \times 10^{24} \mathrm{D} / \mathrm{m}^{2}$. The peak temperatures of the release spectra are indicated in the figure.

The total $\mathrm{D}$ amount released in form of hydrogen molecules (i.e., as $\mathrm{D}_{2}$ and $\mathrm{HD}$ ) was determined from the TPD spectra (for calibration see Sect. 2.6) and is listed in Table 1. Surprisingly, in each of the three $\mathrm{WN}_{\mathrm{x}}$ samples the amount of D released as molecular hydrogen is roughly a factor of 5 lower than the total retained amount of D measured by NRA. The ratio between TPD and NRA is about $18 \%$ and it is almost the same for all the three samples.

Before trying to explain the large difference between the TPD- and NRA-determined D amounts in Tab. 1, it is worth to mention the following information. For pure W samples, NRA depth profiling is normally performed with several different projectile energies up to $4.5 \mathrm{MeV}[14,26]$ such that the D retention up to a depth of $\sim 8 \mu \mathrm{m}$ can be determined. It has been demonstrated that the retained $\mathrm{D}$ amount 
measured by NRA and the released D amount by TPD in magnetron-sputtered W films with thickness smaller than this probing depth are in good agreement with each other [14]. For pure W samples with D retained beyond the NRA probing depth, TPD measurements show always a larger amount of released D than the retained D amount by NRA. However, if there are additional loss channels for D retained in the sample that cannot be included in the final D amount calculation from TPD measurements, the NRAmeasured amount may also exceed that of TPD. In the experiments described here, the thickness of the Dcontaining layer in the $\mathrm{WN}_{\mathrm{x}}$ films is much smaller than the information depth of the applied NRA measurement. This means NRA measures here the total retained $\mathrm{D}$ amount in $\mathrm{WN}_{\mathrm{x}}$. The much lower TPDmeasured D amount clearly points to the fact that D is released in form of other gas species than $3 \mathrm{amu} / \mathrm{q}$ (HD) and $4 \mathrm{amu} / \mathrm{q}\left(\mathrm{D}_{2}\right)$.
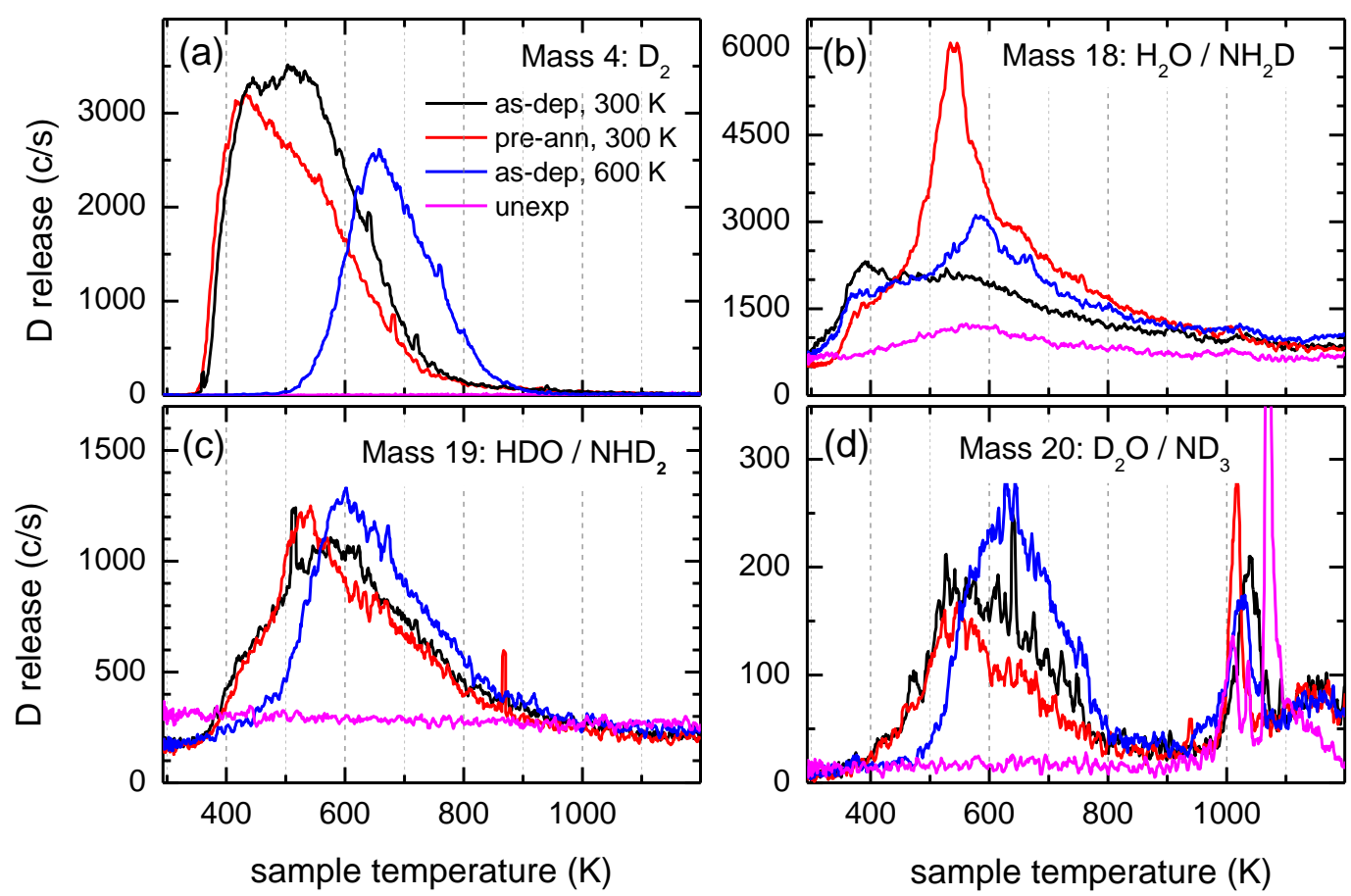

Fig. 9: Comparison of the TPD spectra of different mass channels between $W N_{x}$ samples exposed to a $D$ fluence of $6 \times 10^{24} \mathrm{D} / \mathrm{m}^{2}\left(-200 \mathrm{~V}\right.$ bias, 300/600 K) and an unexposed $W N_{x}$ sample: (a) 4 amu/q; (b) 18 amu/q; (c) $19 \mathrm{amu} / \mathrm{q}$ and (d)20 amu/q. No signal of $D$ or deuterated ammonia is found in the unexposed $W N_{x}$ sample.

Although deuterated ammonia isotopologues, such as $\mathrm{NH}_{2} \mathrm{D}(18), \mathrm{NHD}_{2}(19)$ and $\mathrm{ND}_{3}$ (20), cannot be distinguished from water isotopologues, such as $\mathrm{H}_{2} \mathrm{O}(18)$, $\mathrm{HDO}(19)$ and $\mathrm{D}_{2} \mathrm{O}(20)$, we can still compare the release spectra on the corresponding mass channels from the three different D-implanted samples with a not-implanted sample for qualitative understanding, as plotted in Fig. 9. We find significant release peaks on mass channels 18,19 , and $20 \mathrm{amu}$ in the same temperature range where the $\mathrm{HD}$ and $\mathrm{D}_{2}$ release occurs. For these 3 mass channels we find no corresponding release peaks from the $\mathrm{WN}_{\mathrm{x}}$ sample that was not implanted with D. From this comparison we conclude that a certain amount of D from the D-implanted samples is released in form of deuterated ammonia and water. Unfortunately, these mass channels cannot be calibrated as discussed in Sect. 2.7. Nevertheless, from the experimental findings that only about $18 \%$ of the retained D is released as molecular hydrogen and that release of deuterated ammonia and water isotopologues is clearly proven by TPD we draw the conclusion that a significant amount - of the order of $80 \%$ - of the retained D is released as deuterated ammonia and water. The apparent contradiction to the 
finding that no significant amount of $\mathrm{N}$ is converted to ammonia is due to the facts that, firstly, the total amount of $\mathrm{N}$ in the $\mathrm{WN}_{\mathrm{x}}$ layer is about a factor of 23 higher than the $\mathrm{D}$ amount ( $\mathrm{D}$ amount $\approx 2 \times 10^{20} \mathrm{D} / \mathrm{m}^{2}$ see Fig. 7), secondly, that some D might be released as water and, thirdly, that for the formation of ammonia three hydrogen atoms are required.

\section{WNx erosion due to D plasma exposure}

\subsection{WNx erosion in D plasma}

The erosion of the $\mathrm{WN}_{\mathrm{x}}$ layer after $\mathrm{D}$ implantation was determined by RBS using a $1.5 \mathrm{MeV}{ }^{4} \mathrm{He}^{+}$ion beam. Before discussing the experimental results we would like to make the following comment. The applied substrate bias in the present experiments $(-200 \mathrm{~V})$ is not high enough that the dominant $\mathrm{D}$ ion species $\left(\mathrm{D}_{3}{ }^{+}\right)$and also minor species $\mathrm{D}_{2}{ }^{+}$can sputter W. Only the minority species $\mathrm{D}^{+}$exhibits an energy that is just above the threshold as to sputter W. However, due to the low fluence of $\mathrm{D}^{+}$minority the total sputtered W amount would be too low to be detectable by RBS. Applying the sputter yield for $215 \mathrm{eV} \mathrm{D}$ on $\mathrm{W}$ of $2.3 \times 10^{-5} \mathrm{~W} / \mathrm{D}$ published by Eckstein [27] yields the sputtered tungsten amount for the highest investigated $\mathrm{D}$ fluence $\left(6 \times 10^{24} \mathrm{D} / \mathrm{m}^{2}\right)$ of $1.4 \times 10^{18} \mathrm{~W} / \mathrm{m}^{2}$. This is still less than one monolayer. It should, however, be kept in mind that, although $\mathrm{D}$ can under these conditions not sputter pure $\mathrm{W}$ it has sufficient energy to sputter N. Because the D species cannot explain the measured W erosion, the sputtering of W from the $\mathrm{WN}_{\mathrm{x}}$ layers during the $\mathrm{D}$ plasma exposure is attributed to impurity ions contained in the plasma [18].
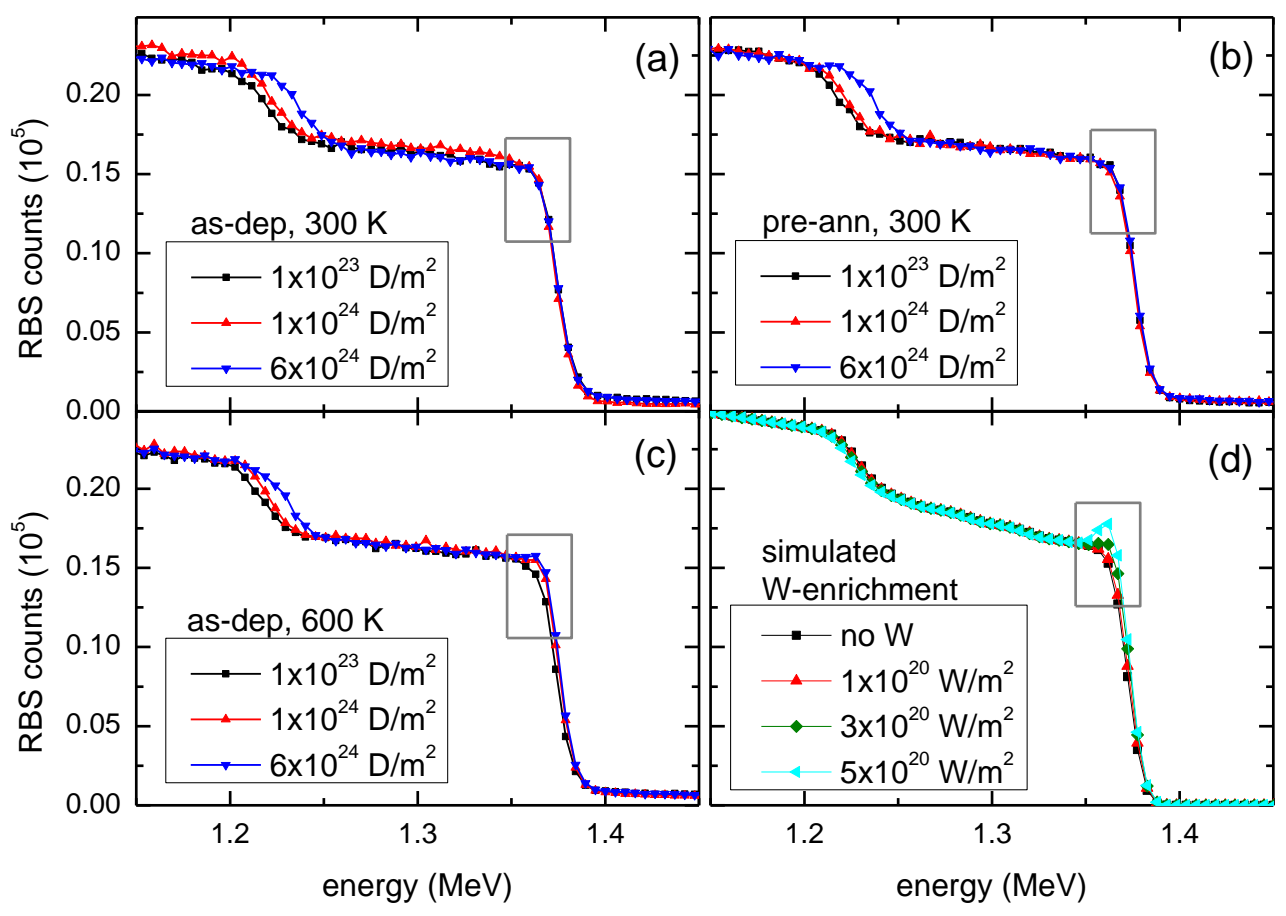

Fig. 10: RBS spectra of magnetron-sputtered $W N_{x}$ films deposited on 2- $\mu$ - $W$-film-coated-Si substrates after $D$ plasma exposure with different $D$ fluences: a) as-deposited samples exposed at $300 \mathrm{~K}$; b) pre-exposureannealed samples exposed at $300 \mathrm{~K} ; \mathrm{c}$ ) as-deposited samples exposed at $600 \mathrm{~K} ; \mathrm{d}$ ) simulated $\mathrm{W}$ enrichment with different thicknesses of W layer on top of a $W N_{x}$ sample. 
The shift of the $\mathrm{W} / \mathrm{WN}_{\mathrm{x}}$ edges at about $1220 \mathrm{keV}$ backscatter energy in the RBS spectra is hardly detectable if the $\mathrm{D}$ fluence is lower than $1.0 \times 10^{24} \mathrm{D} / \mathrm{m}^{2}$. This is the reason why only some selected RBS spectra are shown in each sub-figure of Fig. 10. In sub-figures a-c an obvious shift of the $\mathrm{WN}_{\mathrm{x}}$ edge to higher energy is visible after exposure to a $D$ fluence of $6.0 \times 10^{24} \mathrm{D} / \mathrm{m}^{2}$. The largest shift is found in Fig. $10 \mathrm{~b}$ for the pre-annealed samples implanted at $300 \mathrm{~K}$. In this case about $16 \mathrm{~nm}$ of $\mathrm{WN}_{\mathrm{x}}$ were removed during D

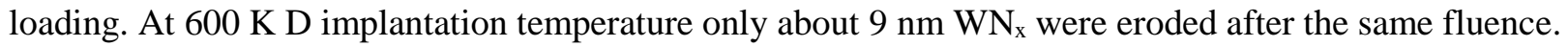

A detailed comparison of the three sets of RBS spectra shows also a slightly different erosion behavior of $\mathrm{WN}_{\mathrm{x}}$ at the two investigated temperatures. For the samples exposed at $600 \mathrm{~K}$ (Fig. 10c) the W counts directly at the surface (i.e., at $\sim 1370 \mathrm{keV}$ backscattering energy; area marked by the rectangles) show a slight increase as the D fluence increases. A corresponding increase is not found for the samples exposed at $300 \mathrm{~K}$ (Fig. 10a, b). To explain this increase of the count rate, SIMNRA simulations were performed, where a thin pure $\mathrm{W}$ layer with different thickness was added on top of the $\mathrm{WN}_{\mathrm{x}}$ layer. The simulated RBS spectra are shown in Fig. 10d. The simulations are performed such that the total $\mathrm{W}$ amount in the whole layer system is kept constant. Nitrogen is removed from a surface layer with increasing thickness. The W from the removed W:N layer is condensed into a pure W layer with the identical total W amount. Fig. 10d illustrates how RBS spectra should evolve if $\mathrm{W}$ enrichment (or $\mathrm{N}$ depletion) at the surface increases. Comparing Figs. 10c and d suggests that the observed increase in count rate at the surface can be explained by $\mathrm{W}$ enrichment at $\mathrm{WN}_{\mathrm{x}}$ surfaces exposed to D plasma at $600 \mathrm{~K}$. The $\mathrm{W}$ enrichment required to explain the observed changes in the spectra is, however, relatively substantial. It amounts to approximately $3 \times 10^{20} \mathrm{Wm}^{-2}$ which corresponds to roughly 30 monolayers of pure tungsten. For the $300-\mathrm{K}$ exposed $\mathrm{WN}_{\mathrm{x}}$ surfaces (Fig. 10a and b), a possible W enrichment is not detectable with RBS. Obviously, at $300 \mathrm{~K}$ exposure the $\mathrm{W}$ enrichment at the surface is less pronounced than at $600 \mathrm{~K}$ such that it cannot be resolved by RBS.

\section{$5.2 \mathrm{~N}$ depletion and $W$ enrichment}

As just discussed, analysis of the RBS spectra of $\mathrm{WN}_{\mathrm{x}}$ surfaces after $\mathrm{D}$ implantation suggests a slight enrichment of $\mathrm{W}$ or a depletion of $\mathrm{N}$ at sample surfaces after exposures at $600 \mathrm{~K}$, while at $300 \mathrm{~K}$, no $\mathrm{W}$ enrichment is detectable by RBS. To further investigate this issue, $\mathrm{WN}_{\mathrm{x}}$ samples before and after D implantation were analyzed by XPS sputter depth profiling. The investigated D-implanted sample was previously exposed to a $\mathrm{D}$ fluence of $5 \times 10^{23} \mathrm{D} / \mathrm{m}^{2}$ at 300 and $600 \mathrm{~K}$. The analysis in the present work focuses on the $\mathrm{N} 1$ s peak at $\sim 397 \mathrm{eV}$ and the most intense tungsten peak, $\mathrm{W} 4 \mathrm{f} 7 / 2$ at $\sim 32 \mathrm{eV}$. Unfortunately, only few data can be found in the literature on XPS peak shifts for $\mathrm{W}$ due to $\mathrm{W}$-nitride formation. The $\mathrm{N} 1 \mathrm{~s}$ peak for tungsten nitrides is shifted to lower binding energies compared with molecular nitrogen adsorbed on the $\mathrm{W}$ surface, which has a binding energy of about $400.0 \mathrm{eV}[28,29]$. The values for $\mathrm{N}$ bonded to $\mathrm{W}$ reported in the literature vary from 397.0 to $397.7 \mathrm{eV} \mathrm{[17,30-35].} \mathrm{More} \mathrm{literature} \mathrm{data} \mathrm{are} \mathrm{available} \mathrm{for} \mathrm{the}$ $\mathrm{W} 4 \mathrm{f}$ peak. The metallic $\mathrm{W} 4 \mathrm{f} 7 / 2$ peak exhibits a binding energy of $31.4 \mathrm{eV}$ and the nitrides generally show slightly higher values. Also in this case some scatter in the published data is noticed. Different values for the binding energy of the $\mathrm{W} 4 \mathrm{f} 7 / 2$ peak in $\mathrm{W}$ nitrides ranging from 31.4 to $33.2 \mathrm{eV}$ were reported in different publications and attributed to different nitride stoichiometries [30-35].

The XPS spectra in the binding energy ranges of these two peaks are shown in Fig. 11. As one can see in Fig. 11a, without D implantation, the here investigated W 4f7/2 peak of the as-deposited layer (squares) is located at $32.4 \mathrm{eV}$. After D implantation at either temperature, it shifts to lower binding energy $(31.4 \mathrm{eV})$ with roughly $50 \%$ higher intensity at $300 \mathrm{~K}$ and even higher intensity at $600 \mathrm{~K}$. According to the published peak positions listed above the latter peak position is the $\mathrm{W} 4 \mathrm{f} 7 / 2$ peak position of metallic W. Similarly, Fig. 11b shows the change of the $\mathrm{N}$ 1s peak after $\mathrm{D}$ implantation: the integral of the counts from the $\mathrm{N} 1 \mathrm{~s}$ peak decreases by more than $50 \%$ at $300 \mathrm{~K}$ and is negligible at $600 \mathrm{~K}$. The binding energy at both 
temperatures shifts by only $0.2 \mathrm{eV}$ from $397.4 \mathrm{eV}$ to $397.6 \mathrm{eV}$. Both, the higher $\mathrm{W} 4 \mathrm{f}$ peaks intensity and the lower $\mathrm{N} 1 \mathrm{~s}$ intensity point to a higher $\mathrm{W}$ concentration in the surface after D implantation at both temperatures.
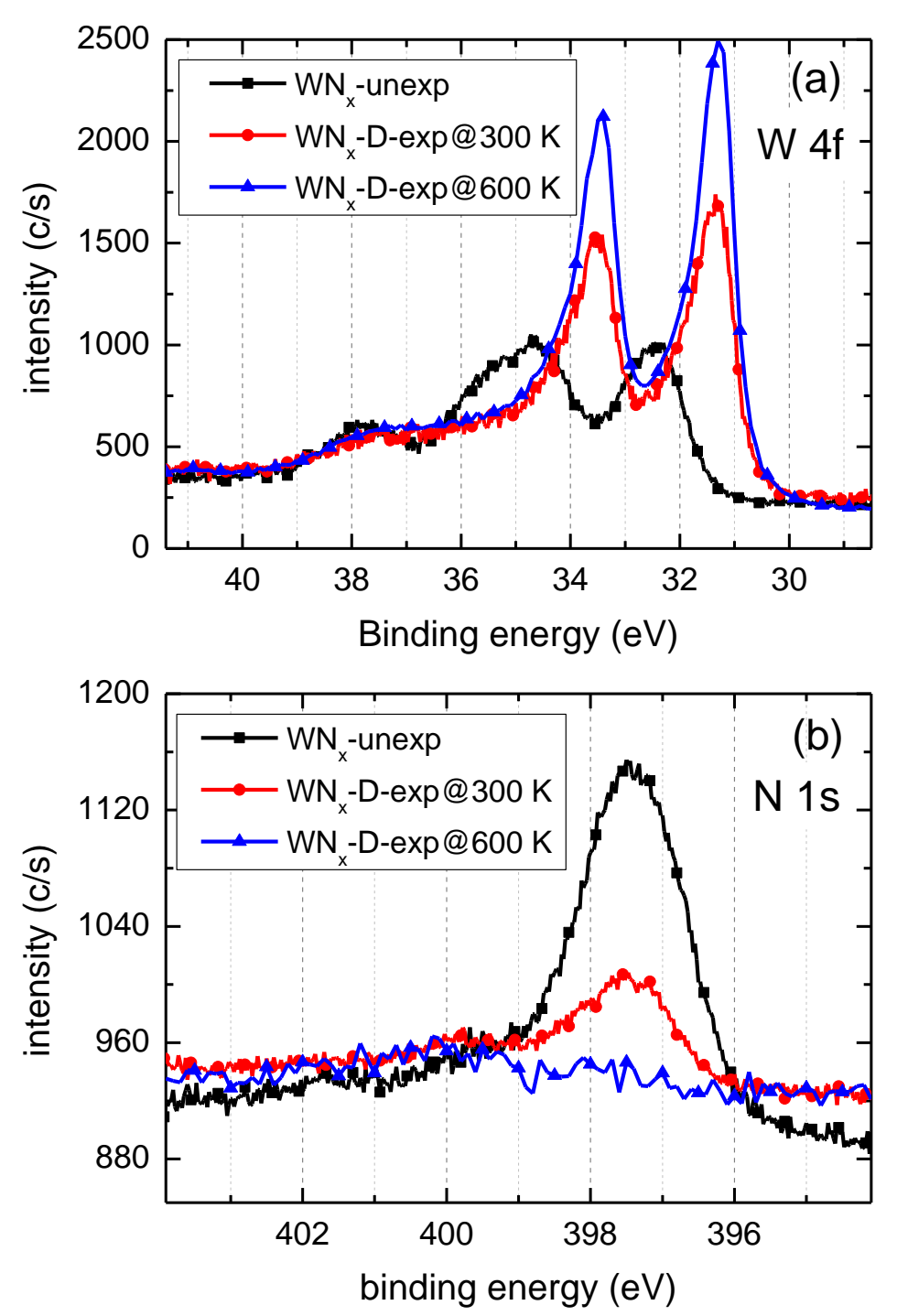

Fig. 11: XPS spectra of $W N_{x}$ surface before and after exposure to D plasma to a fluence of $5 \times 10^{23} \mathrm{D} / \mathrm{m}^{2}$. (a) $W 4 f$ doublet, (b) $N 1$ s peak. Due to the D plasma exposure, the two $W 4 f$ peaks shift to the direction of metallic $W 4 f$. In addition, the $N$ ls peak intensity decreases significantly.

Although not being resolved in RBS spectra, XPS measurements on sample surfaces exposed to D plasma at $300 \mathrm{~K}$ also showed $\mathrm{W}$ enrichment. Hence XPS sputter depth profiling was performed on both surfaces exposed to D plasma to a fluence of $5 \times 10^{23} \mathrm{D} / \mathrm{m}^{2}$ at 300 and $600 \mathrm{~K}$. An unexposed $\mathrm{WN}_{\mathrm{x}}$ sample was also measured for comparison. The measured depth profiles are shown in Fig. 12 as a function of Ar fluence. Plotted in this figure are only the $\mathrm{W}$ and $\mathrm{N}$ fractions (normalized such that $\mathrm{W}+\mathrm{N}=100 \%$ ). In the measurement we also find traces of impurities (in particular at the very surface), but these impurities are not considered to be relevant for the further interpretation of the W:N ratio and for sake of clarity they are, therefore, not shown in the figure. The first 2 data points of each depth profile are taken prior to Ar sputtering. They are influenced by the presence of surface adsorbents. Therefore, the $\mathrm{W}: \mathrm{N}$ ratio of these 
data points can be influenced by adsorbed nitrogen. The detected impurities are shortly discussed further below. No particular effort was made to reach a reliable quantitative interpretation of the XPS data. Due to impurity adsorption during transport through air and preferential sputtering effects the quantitative interpretation of XPS depth profiles of such $\mathrm{WN}_{\mathrm{x}}$ layers is inherently difficult. Nevertheless, a qualitative interpretation of the XPS sputter depth profiles, i.e., the relative differences between the different samples, is possible. And the basic question we want to answer with the XPS depth profiles here is whether or not there is a different $\mathrm{W}$ enrichment at the sample surface after D exposure at 300 and $600 \mathrm{~K}$.

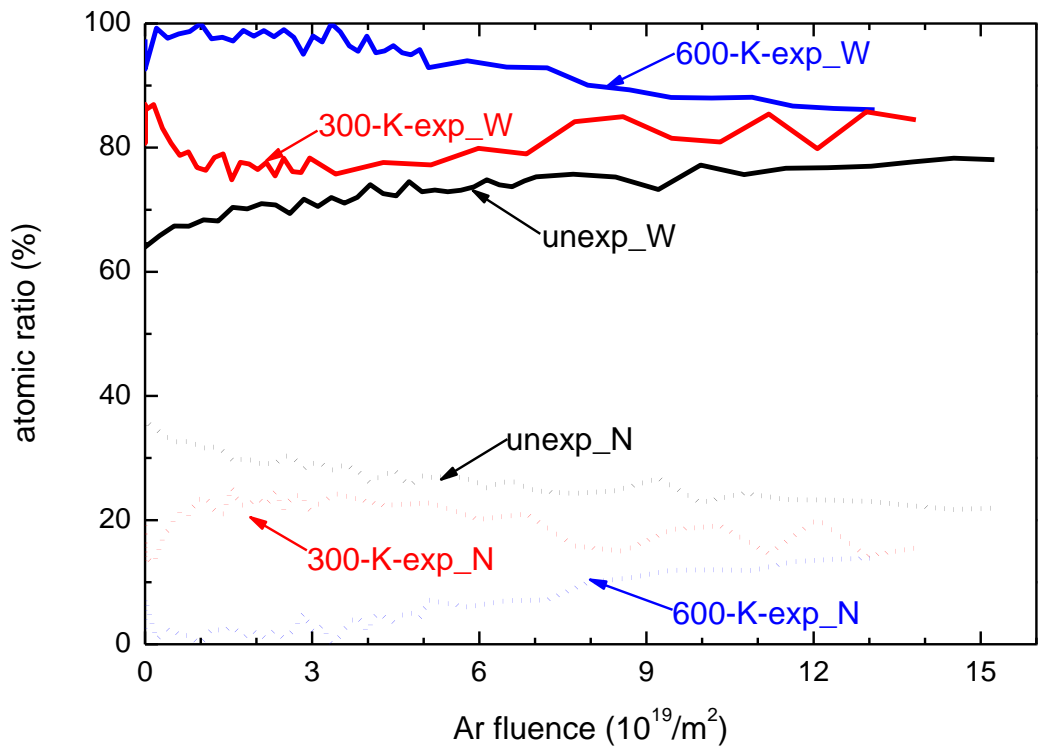

Fig. 12: Ar-sputter XPS depth profiles of unexposed $W N_{x}$ and $W N_{x}$ after exposure to D plasma to a fluence of $5 \times 10^{23} \mathrm{D} / \mathrm{m}^{23}$ at 300 and $600 \mathrm{~K}$.

The as-deposited (i.e., unexposed) sample shows initially a slight increase of the $\mathrm{W}$ and a corresponding decrease of the $\mathrm{N}$ fraction. This transient change in surface composition is assumed to be due to preferential sputtering of $\mathrm{N}$ during Ar sputter depth profiling. It seems that after about half of the measurement the surface concentrations reach a steady state value with a $W: N$ ratio of about 75:25. Surprisingly, the initial $\mathrm{W}: \mathrm{N}$ ratio of about 65:35 is significantly higher than the W:N ratio determined by RBS (56:44, see Sect. 3). The reason for that is not fully clear, but it is attributed to uncertainties in the evaluation of the XPS data. The fact that the steady-state W:N ratio of about 75:25 differs from the initial value is attributed to preferential sputtering. During sputtering with Ar, nitrogen is preferentially eroded from the surface such that the W fraction within the XPS information depth (about 3 to $5 \mathrm{~nm}$ ) is increased.

The sample exposed to D plasma at $300 \mathrm{~K}$ shows a significantly higher $\mathrm{W}$ surface concentration than the unexposed sample. This is in agreement with the anticipated removal of $\mathrm{N}$ from the surface due to $\mathrm{D}$ implantation (see also in Fig. 11). After an Ar fluence of about 2 to $3 \times 10^{19} \mathrm{Ar} / \mathrm{m}^{2}$ the W:N ratio approaches the values measured for the unexposed sample. The remaining difference between the unexposed and 300$\mathrm{K}$-exposed samples is attributed to uncertainties in the XPS evaluation.

The sample exposed to D plasma at $600 \mathrm{~K}$ has a much higher $\mathrm{W}$ surface concentration and this higher $\mathrm{W}$ concentration extends to a much larger depth than for the $300-\mathrm{K}$ case. The $\mathrm{N}$ content close to the surface is almost zero and it starts to increase for Ar fluences larger than about $4 \times 10^{19} \mathrm{Ar} / \mathrm{m}^{2}$. The required $\mathrm{Ar}$ fluence to reach a quasi-steady-state is about $10 \times 10^{19} \mathrm{Ar} / \mathrm{m}^{2}$. This is about 3 times more than for the 300$\mathrm{K}$-exposed sample. Towards the end of the measurement all 3 samples seem to approach a common steady- 
state value. This behavior is anticipated because after removal of the surface layer modified by the $\mathrm{D}$ plasma exposure the underlying $\mathrm{WN}_{\mathrm{x}}$ layers are more or less identical. In spite of the remaining uncertainties in the absolute W:N ratios we can state that from XPS sputter depth profiling a clear W enrichment at the surface was found and that the thickness of this $\mathrm{W}$-enriched layer is about a factor 3 larger for the sample exposed at $600 \mathrm{~K}$ as compared with the sample exposed at $300 \mathrm{~K}$.

The total sputter crater depth after argon sputtering was not measured, but assuming that the rate determining step is sputtering of $\mathrm{W}$ by Ar we can estimate the removed $\mathrm{W}$ amount. The sputter yield for $10 \mathrm{keV} \mathrm{Ar}$ on $\mathrm{W}$ is about 2.3 [27]. That means that after the longest applied Ar fluence of $1.5 \times 10^{20} \mathrm{Ar} / \mathrm{m}^{2}$ about $3.4 \times 10^{20} \mathrm{~W} / \mathrm{m}^{2}$ were removed. This corresponds to the $\mathrm{W}$ amount in an approximately $8.5 \mathrm{~nm}$ thick layer of our $\mathrm{WN}_{\mathrm{x}}$ film (for comparison: the thickness of a corresponding bulk tungsten layer would be $5.4 \mathrm{~nm}$ ). Taking this value as a rough estimate for the sputter depth scale, we arrive at the following numbers. The depth to reach a steady-state value of the W:N ratio in the unexposed sample due to preferential sputtering of $\mathrm{N}$ by Ar is about $4.0 \mathrm{~nm}$. The found $\mathrm{W}$ enrichment for the $300-\mathrm{K}$-exposed sample corresponds to about 1.5 to $2.0 \mathrm{~nm}$ and for the $600-\mathrm{K}$-exposed sample 5.0 to $6.0 \mathrm{~nm}$. This observation is in agreement with the RBS results presented in Sect. 5.1 which also indicated a stronger W enrichment for the sample exposed to $\mathrm{D}$ at $600 \mathrm{~K}$. The reason for this stronger $\mathrm{N}$ removal at $600 \mathrm{~K}$ is presently not known. A possible explanation is that the removal of $\mathrm{N}$ by $\mathrm{D}$ is more efficient at higher temperature due to an enhanced diffusion or chemical reactivity.

\subsection{N content}

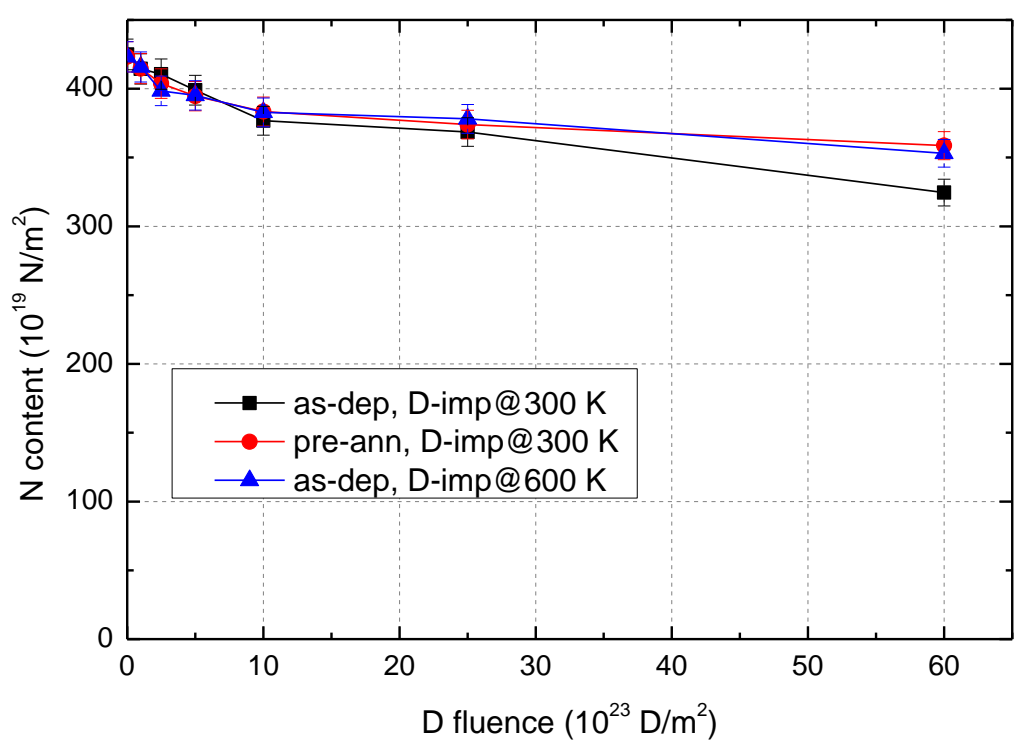

Fig. 13: Amount of $N$ in $W N_{x}$ samples as function of $D$ fluence as deduced from the shift of the RBS tungsten edge and height. The decrease of $N$ in the $W N_{x}$ layer is in general rather small.

XPS measurements show the removal of $\mathrm{N}$ from the surface after $\mathrm{D}$ plasma exposure. To determine how much $\mathrm{N}$ in $\mathrm{WN}_{\mathrm{x}}$ is removed by $\mathrm{D}$, the remaining $\mathrm{N}$ amount in $\mathrm{WN}_{\mathrm{x}}$ layers after $\mathrm{D}$ plasma exposure was extracted from the simulation of the RBS spectra as described before (see in Sec. 2.5). The nitrogen areal densities measured by RBS are plotted as a function of D fluence in Fig. 13. The initial N content prior to $\mathrm{D}$ exposure is for all samples identical within the experimental uncertainty. This also proves that the pre-exposure annealing at $600 \mathrm{~K}$ does not change the $\mathrm{N}$ content, i.e., no desorption of $\mathrm{N}$ from the $\mathrm{WN}_{\mathrm{x}}$ 
layers occurs at $600 \mathrm{~K}$ for the here deposited $\mathrm{WN}_{\mathrm{x}}$ layers. In general, the $\mathrm{N}$ amount decreases with increasing D fluence for all the three groups of samples. The decrease is almost identical for all 3 sets of samples. It seems to be slightly higher for the as-deposited samples with D implantation at $300 \mathrm{~K}$. The total decrease of the $\mathrm{N}$ content after the maximum fluence of $6 \times 10^{24} \mathrm{D} / \mathrm{m}^{2}$ correspond to about $18 \%$.

\section{Discussion}

The new analysis method presented in Sect. 2.5 comprising low-energy Ar plasma sputtering combined with NRA analysis of D retention is capable of resolving the D depth profile at the surface with a depth resolution of less than $3 \mathrm{~nm}$ which is superior to the standard NRA depth resolution (16 $\mathrm{nm}$ in our set-up for the analysis of the alpha particles from the nuclear reaction, see $[14,26])$. This allows resolving the implantation depth profile of low-energy $(215 \mathrm{eV}) \mathrm{D}$ implanted into $\mathrm{WN}_{\mathrm{x}}$ layers.

$\mathrm{D}$ implanted at $300 \mathrm{~K}$ into $\mathrm{WN}_{\mathrm{x}}$ layers is found in a near surface layer with a thickness of about $19 \mathrm{~nm}$ (Figs. 4 and 5). Comparison with SDTrimSP simulation results (Fig. 6) yields that this thickness corresponds to the implantation depth of the small fraction of atomic $\mathrm{D}^{+}$ions which impinge with the full energy of $215 \mathrm{eV}$. The molecular ions, $\mathrm{D}_{3}{ }^{+}$and $\mathrm{D}_{2}{ }^{+}$, have a lower energy per deuteron and correspondingly a smaller penetration depth. From this good agreement we draw the conclusion that at $300 \mathrm{~K}$ the implanted $\mathrm{D}$ does not diffuse, but stays where it is implanted. The retained $\mathrm{D}$ amounts are of the order of $2 \times 10^{20} \mathrm{D} / \mathrm{m}^{2}$ (Fig. 7). The fraction of impinging D that is retained is very low. Even for the lowest investigated fluence of $1 \times 10^{23} \mathrm{D} / \mathrm{m}^{2}$ only a fraction of $10^{-3}$ of the impinging deuterons is retained. In this context it should, however, be kept in mind that the reflection yield calculated with SDTrimSP for the conditions of this experiment is 0.49 for the majority ions. The saturation of the retained amount sets in at a fluence of about $1 \times 10^{24} \mathrm{D} / \mathrm{m}^{2}$. That also means that most of the implanted deuterons must diffuse back to the surface and desorb. We assume that within the ion penetration range $\mathrm{D}$ can diffuse due to ion-impact-induced diffusion.

At $600 \mathrm{~K}$ the $\mathrm{D}$ depth profile is significantly broader than that at $300 \mathrm{~K}$. The total retained $\mathrm{D}$ and the local $\mathrm{D}$ concentrations are lower, but the penetration depth is much larger than the implantation range. This is a clear proof that at $600 \mathrm{~K} \mathrm{D}$ diffuses into larger depth. Comparing the penetration in $\mathrm{WN}_{\mathrm{x}}$ layers with that in pure $\mathrm{W}[14,15,23-25]$ we find that the range for $\mathrm{WN}_{\mathrm{x}}$ is much lower than for $\mathrm{W}$. That means that the diffusion coefficient of $\mathrm{D}$ in $\mathrm{WN}_{\mathrm{x}}$ is much lower than that in bulk W. In addition, the $\mathrm{D}$ concentration in the $\mathrm{WN}_{\mathrm{x}}$ layer is much higher than in pure $\mathrm{W}$ (about 14 at.\% at $300 \mathrm{~K}$ ). The maximum $\mathrm{D}$ concentration is found almost at the end of the implantation range of the $\mathrm{D}$ species with the highest energy (the $\mathrm{D}^{+}$ions impinging with $215 \mathrm{eV}$, see Fig. 6). For D implantation at $600 \mathrm{~K}$ the peak concentration is about 3\%. The total retained D amount at $600 \mathrm{~K}$ is only about half of that at $300 \mathrm{~K}$. To check whether the reduced D retention at $600 \mathrm{~K}$ is due to a change of the microstructure or due to the higher implantation temperature, one sample was first annealed at $600 \mathrm{~K}$ for $2 \mathrm{~h}$ and then exposed to D plasma at $300 \mathrm{~K}$. This sample shows about $10 \%$ lower D retention than the sample that was not pre-annealed (see Fig. 7). From this we conclude that the pre-annealing does not lead to a significant change of the retention capability and that, therefore, the lower total retention at $600 \mathrm{~K}$ is due to the higher implantation temperature. The slightly lower retained $\mathrm{D}$ amount in pre-annealed samples compared with as-deposited samples may be due to the fact that the preexposure annealing moderately annihilated some trapping sites inside the $\mathrm{WN}_{\mathrm{x}}$ layer. Such a minor change could also explain the small increase of the decomposition temperature of the layer after annealing as presented in Fig. 1. Based on the observation that the pre-annealed sample shows only a $10 \%$ lower D retention we conclude that the lower local $\mathrm{D}$ concentration at $600 \mathrm{~K}$ is not governed by the annealing of possible trap sites, but is dominantly attributed to thermal detrapping during $\mathrm{D}$ exposure which leads to a lower occupation of available trap sites. The fact that thermal detrapping is active at these temperatures is clearly shown in the TPD spectra of Figs. 8 and 9. 
The $\mathrm{D}$ concentration in $\mathrm{WN}_{\mathrm{x}}$ exposed to $\mathrm{D}$ plasma at $600 \mathrm{~K}$ is significantly higher than in pure $\mathrm{W}$ materials in the region beyond the implantation depth. The mean $\mathrm{D}$ concentration in $\mathrm{WN}_{\mathrm{x}}$ in the range from about 15 to $50 \mathrm{~nm}$ is roughly $1 \%$. For similar loading conditions the $\mathrm{D}$ concentration in pure $\mathrm{W}$ materials is typically of the order of $10^{-3}$ for the depth range from about $16 \mathrm{~nm}$ up to a few $\mu \mathrm{m}[14,15,24,25]$ at $300 \mathrm{~K}$ and much lower at $600 \mathrm{~K}\left(10^{-4}\right)$ [24]. Magnetron-sputtered W films normally exhibit 3-4 times higher $\mathrm{D}$ concentration than that in warm-rolled polycrystalline $\mathrm{W}[14,15,25]$. The $\mathrm{D}$ concentration in our $\mathrm{WN}_{\mathrm{x}}$ layers is about a factor of 4 higher than that in magnetron-sputtered $\mathrm{W}$ films. We suggest that $\mathrm{N}$ in the $\mathrm{W}$ matrix acts as a trap site for D thus significantly enhancing D retention in comparison with pure W. Noteworthy is the stable bonding of the $\mathrm{D}$ retained in the $\mathrm{WN}_{\mathrm{x}}$ layers. It was observed for pure $\mathrm{W}$ that up to $30 \%$ of the retained D is lost from the sample after storage for 2 months. However, this is not the case for our $\mathrm{WN}_{\mathrm{x}}$ samples. NRA measurements performed on these samples at different times after exposure, namely 1 day, 3 weeks and 3 months after D implantation, showed within the experimental uncertainty the identical D amount. This means there is almost no loss of $\mathrm{D}$ in $\mathrm{WN}_{\mathrm{x}}$ layers during storage.

Intriguing is the decrease of the total retained $\mathrm{D}$ amount with increasing $\mathrm{D}$ fluence at low fluence (below $1 \times 10^{24} \mathrm{D} / \mathrm{m}^{2}$, see Fig. 7) in both samples exposed at $300 \mathrm{~K}$. As mentioned in Sect. 3.2 this behavior is reproducible. Since D does not diffuse in $\mathrm{WN}_{\mathrm{x}}$ at $300 \mathrm{~K}$, the final retained $\mathrm{D}$ amount in $\mathrm{WN}_{\mathrm{x}}$ at $300 \mathrm{~K}$ depends strongly on the amount of $\mathrm{D}$ trap sites within the implantation zone. In the preceding paragraph we speculated that the $\mathrm{D}$ retention in $\mathrm{WN}_{\mathrm{x}}$ is governed by bonding to $\mathrm{N}$. At very low $\mathrm{D}$ fluence $\mathrm{N}$ is abundant at the top-most surface and we assume that initially the retained D amount increases linearly with D fluence. But, as the $\mathrm{D}$ fluence increases more and more $\mathrm{N}$ will be removed from the implantation region. It is conceivable that a certain fraction of the initially retained $\mathrm{D}$ is released together with the $\mathrm{N}$ thus leading to a decrease of the retained $\mathrm{D}$ amount with increasing $\mathrm{D}$ fluence. At a certain $\mathrm{D}$ fluence, probably when most of the $\mathrm{N}$ is removed from the implantation zone, the total retained $\mathrm{D}$ will decrease to a minimum. After that transition period the total retained D amount again starts to increase slowly with D fluence. For D implantation into $\mathrm{WN}_{\mathrm{x}}$ at $600 \mathrm{~K}$, the thermal detrapping and also the diffusion of the implanted $\mathrm{D}$ come into play. Therefore, the decrease at low $\mathrm{D}$ fluence is much less pronounced as that at $300 \mathrm{~K}$. It is, unfortunately, not feasible to investigate lower D fluences in PlaQ due to the relatively high ion flux. Further experiments in another device with much lower ion flux are planned in the near future.

\section{Summary}

The interaction of D plasma with sputter-deposited $\mathrm{WN}_{\mathrm{x}}$ layer was studied at two temperatures, 300 and $600 \mathrm{~K}$. TPD measurements have shown that the sputter-deposited $\mathrm{WN}_{\mathrm{x}}$ layers are thermally stable up to about $800 \mathrm{~K}$. Decomposition starts at around $830 \mathrm{~K}$ with two release peaks at 925 and $960 \mathrm{~K}$. A new D depth profiling method consisting of low-energy Ar sputtering combined with NRA analysis of the remaining $\mathrm{D}$ amount shows great potential in resolving $\mathrm{D}$ depth distribution with a few nanometers resolution. The new method allowed the determination of D depth profiles by NRA with unprecedented depth resolution of $3 \mathrm{~nm}$. Results show that at $300 \mathrm{~K}$ the implanted D is retained only within the implantation zone. At $600 \mathrm{~K} \mathrm{D}$ diffuses to larger depth, but the diffusivity of $\mathrm{D}$ in $\mathrm{WN}_{\mathrm{x}}$ is substantially lower than in pure $\mathrm{W}$. It appears that $\mathrm{WN}_{\mathrm{x}}$ acts as a diffusion barrier for diffusion of $\mathrm{D}$ in $\mathrm{W}$, but further investigations are necessary to support this assumption. The local concentration of $\mathrm{D}$ retained in $\mathrm{WN}_{\mathrm{x}}$ beyond the implantation zone after exposure at $600 \mathrm{~K}$ is relatively high. It is about a factor of 10 higher than in standard polycrystalline tungsten and a factor of 3 higher than in sputter-deposited pure W films exposed at $300 \mathrm{~K}$. This relatively high local D concentration is attributed to the presence of $\mathrm{N}$ which is suggested to act as a trap for hydrogen isotopes. Results from both RBS and XPS measurements show different processes on the $\mathrm{WN}_{\mathrm{x}}$ surfaces exposed at different temperatures. The $\mathrm{W}$ enrichment and $\mathrm{N}$ 
removal are less pronounced at $300 \mathrm{~K}$ than at $600 \mathrm{~K}$. D is thermally released from $\mathrm{WN}_{\mathrm{x}}$ in the temperature range from 400 to $700 \mathrm{~K}$. Surprisingly, only about $18 \%$ of the retained D is released as hydrogen molecules. Based on the available data it was concluded that up to $80 \%$ of the retained D is released as deuterated ammonia or water. At present, these two species cannot be surely distinguished, but it is assumed that ammonia isotopologues dominate. The release of ammonia occurs together with the release of molecular hydrogen.

\section{Acknowledgements}

This work has been carried out within the framework of the EUROfusion Consortium and has received funding from the Euratom research and training programme 2014-2018 under grant agreement No 633053. The views and opinions expressed herein do not necessarily reflect those of the European Commission. The work was partially carried out under WP PFC. The stay of L. Gao at Max-Planck Institute für Plasmaphysik in Garching was partially funded through a Joint Doctoral Promotion Programme between Max-Planck Society and the Chinese Academy of Sciences, which is gratefully acknowledged. Intense discussions with Dr. Klaus Schmid and Dr. Matej Mayer on the interpretation of experimental results are highly appreciated. Thanks are further due to Michael Fußeder and Joachim Dorner for their help with ion beam measurements, and to Stefan Elgeti for his help on FIB cutting.

\section{References:}

[1] Roth J., Tsitrone E., Loarer T. et al. 2008 Plasma Phys. Contr. Fusion 50103001

[2] Neu R., Kallenbach A., Balden M. et al. 2013 J. Nucl. Mater. 438, Supplement S34

[3] Neu R. L., Brezinsek S., Beurskens M. et al. 2014, IEEE Trans. Plasma Sci. 42552

[4] Kallenbach A., Dux R., Fuchs J. C. et al. 2010 Plasma Phys. Contr. F. 52055002

[5] Kallenbach A., Bernert M., Eich T. et al. 2012 Nucl. Fusion 52122003

[6] Zagorski R., Neu R. and ASDEX Upgrade Team. 2012 Contrib. Plasm. Phys. 52379

[7] Oberkofler M., Douai D., Brezinsek S. et al. 2013 J. Nucl. Mater. 438, Supplement S258

[8] Brezinsek S and JET-EFDA contributors. 2015 J. Nucl. Mater. 46311

[9] Rubel M., Philipps V., Marot L. et al. 2011 J. Nucl. Mater. 415 S223

[10] K. Dobes, V. Smejkal, T. Schäfer, F. Aumayr, 2014 Int. J. Mass Spec. 365-366 64

[11] Gao L., Jacob W., Wang P. et al. 2014 Phys. Scripta T159 014023

[12] Lee H. T., Ishida M., Ohtsuka Y. et al. 2014 Phys. Scripta T159 014021

[13] Gao L., Jacob W., Schwarz-Selinger T. et al. 2014 J. Nucl. Mater. 451352

[14] Wang P., Jacob W., Gao L. et al. 2013 Nucl. Instr. Meth. Phys. B 30054

[15] Wang P., Jacob W., Gao L. et al. 2014 Phys. Scripta T159 014046

[16] Salançon E., Dürbeck T., Schwarz-Selinger T. et al. 2011, J. Nucl. Mater. 376160

[17] Schmid K., Manhard A., Linsmeier C. et al. 2010 Nucl. Fusion 50025006

[18] Manhard A., Schwarz-Selinger T. and Jacob W. 2011 Plasma Sources Sci. T. 20015010 Note: Unfortunately, the information given in the last paragraph of this article is not correct, but the information in figures $\overline{5 \text { and }} 6$ is correct. The contribution of the molecular ions to the total ion flux for standard conditions is: $\mathrm{D}_{3}{ }^{+}=94 \%, \mathrm{D}_{2}{ }^{+}=$ $3 \%$ and $D^{+}=3 \%$. Correspondingly, the contributions to the total deuteron flux in form of ions are: $97 \%, 2 \%$, and $1 \%$.

[19] Alimov V. K., Mayer M. and Roth J. 2005 Nucl. Instr. Meth. Phys. B 234169

[20] Mayer M. "SIMNRA user's guide" 1997 IPP Report: IPP 9/113

[21] Möller W., Eckstein W. and Biersack J. P. 1988 Comput. Phys. Commun. 51355 
[22] Mutzke A., Schneider R., Eckstein W. and Dohmen R., 2011 IPP Report 12/08, MaxPlanck-Institut für Plasmaphysik (Hrsg.) (http://edoc.mpg.de/display.epl?mode=doc\&id=552734)

[23] Roth J. and Schmid K. 2011 Phys. Scripta T145 014031

[24] Manhard A., Schmid K., Balden M. et al. 2011 J. Nucl. Mater. 415 S632

[25] Wang P., Jacob W. and Elgeti S. 2015 J. Nucl. Mater. 456192

[26] Schmid K. and von Toussaint U. 2012 Nucl. Instr. Meth. Phys. B 28164

[27] W. Eckstein in Topics in Applied Physics Vol. 110 "Sputtering by Particle Bombardment IV", Springer Verlag, Berlin, 2007, R. Behrisch and W. Eckstein (Eds.), chapter "Sputtering Yields", pages 33-187

[28] Fuggle J. C. and Menzel D. 1979 Surf. Sci. 791

[29] Egawa C., Naito S. and Tamaru K. 1983 Surf. Sci. 13149

[30] Nakajima T., Watanabe K. and Watanabe N. 1987 J. Electrochem. Soc. 1343175

[31] Lee Ch.-W., Kim Y.T. and Min S.-K. 1993 Appl. Phys. Lett. 623312

[32] Kakanakova-Georgieva A., Kassamakova L., Marinova Ts., 1999 Appl. Surf. Sci. 151225

[33] Shen Y.G., Mai Y.W., McKenzie D.R. et al. 2000 J. Appl. Phys. 881380

[34] Baker C.C. and Shah S.I. 2002 J. Vac. Sci. Technol. A 201699

[35] Meisl G., Schmid K., Encke O. et al. 2014 New Journal of Physics 16093018 